\title{
Labor Market Dynamics in Developing Countries: Comparative Analysis using Continuous Time Markov Processes*
}

\author{
Mariano Bosch \\ World Bank \\ William Maloney \\ World Bank
}

\begin{abstract}
This paper studies the dynamics of three developing country labor markets employing recent advances in the estimation of continuous time Markov processes. We first examine the flows of workers among five states: three types of paid labor, unemployment, and out of the labor force. We find a high degree of commonality in patterns of worker flows among the three countries and attempt to compare the flexibility of the markets by examining an index of overall "mobility." Second, we seek to establish whether the issues of advanced country labor markets apply to LDC markets or whether the latter constitute a different phylum. Paralleling the mainstream literature on the role of being out of the labor force as discouraged unemployment, we then identify some common stylized facts about the role of the informal self-employed and salaried sectors and to what degree they serve as a holding pattern vs a desirable alternative to formal sector work. In the process, we identify very strong differences in mobility patterns between men and women and attempt to shed some light on whether these differences arise from discrimination or perhaps instead the constraints imposed by household responsibilities. Finally, we study labor market adjustment across the business cycle in Mexico and identify patterns of job creation and destruction among the three paid sectors and confirm the mainstream view of the role of out of the labor force as a procyclical phenomenon.
\end{abstract}

\section{World Bank Policy Research Working Paper 3583, April 2005}

The Policy Research Working Paper Series disseminates the findings of work in progress to encourage the exchange of ideas about development issues. An objective of the series is to get the findings out quickly, even if the presentations are less than fully polished. The papers carry the names of the authors and should be cited accordingly. The findings, interpretations, and conclusions expressed in this paper are entirely those of the authors. They do not necessarily represent the view of the World Bank, its Executive Directors, or the countries they represent. Policy Research Working Papers are available online at http:/lecon.worldbank.org.

\footnotetext{
* We are very grateful to Carlos Arango for advice in the early phases of this project and to Lucas Siga for help in managing the data.
} 


\section{Introduction}

This paper employs recent advances in the estimation of continuous time Markov processes to study the dynamics of three Latin American labor markets. The goal is two fold. First, we use the average transition matrices and derivative statistics to identify common patterns and establish some stylized facts about labor force dynamics in the developing world. ${ }^{1}$ Second, we seek to establish whether the issues preoccupying the mainstream literature resonate in the developing world, or whether we are dealing with a different phylum of labor markets, altogether. To this end, we complement the average matrices with a time series of instantaneous matrices that depicts the adjustment of the Mexican labor market across the business cycle.

As a central issue in the second agenda, the industrialized world has examined in some detail the relative roles of the states of unemployment and being out of the labor force (OLF) particularly in the context of adjustments during cyclical downturns. Although theoretically the differences between two worker states may be clear- modern matching theory treats it as something of an unpaid chosen state not given to search- the existence of non-negligible flows of workers directly from out of the labor force into employment raises suspicions that OLF may be comprised in fact of the discouraged unemployed. However, Flinn and Heckman (1982), pioneering the use of Markov processes in this field, conclude that, for young men in the US, the two states show very different behavior and Blanchard and Diamond (1989) confirm the distinction finding countercyclical flows from employment to unemployment and procyclical flows into OLF.

Developing country labor markets, in addition to having a substantial OLF sector, feature a similar and long standing ambiguity in the presence of the large "informal" sectors comprised of owners of or workers in small firms who are uncovered by labor legislation. Dating at least from Harris and Todaro (1973), the sector has been equated

\footnotetext{
${ }^{1}$ See Maloney (1999) for an early application of descrete time transition matrices to Mexico.
} 
with underemployment or disguised unemployment- the disadvantage sector of a market segmented by rigidities in the "formal" or covered sector of the economy. However, another emerging view keys more off the mainstream self-employment literature in the style of Lucas (1978), Jovanovic 1982 and Evans and Leighton 1989, and argues that, as a first approximation, the sector should be seen as an unregulated, largely voluntary selfemployed sector. The exaggerated size of the informal sector in LDCs, raises the stakes surrounding the debate dramatically: If the $35 \%-50 \%$ of Latin American labor markets is thought of as disguised unemployed, then the distortions are indeed large. The two views are, of course, compatible to some degree given the heterogeneity of the sector, and existing theory can accommodate this: a turnover based efficiency wage model such as that of Stiglitz (1974) allows for firms raising wages above market clearing to deter workers from entering self-employment and, in the process, creating involuntary informality. As with the OLF/unemployment case, the issue is really one of degree: what the "stylized" view of the functioning of the sector should be.

A second US literature is concerned with understanding the high rates of job creation and destruction that map into large flows of workers in and out of employment, and how these combine to form the overall aggregates generally studied (See Blanchard and Diamond 1989 and Davis and Haltiwanger 1998). The central lesson emerging from this literature is that the cyclical behavior of unemployment is mainly driven by job destruction in downturns and a reduction in destruction in upturns. This higher volatility of the job destruction rate found in the data, has inspired theoretical search modes such as Mortensen and Pissarides (1994), which have now become standard in the literature. This issue clearly takes on another dimension in developing countries when we introduce informal sectors. Extrapolating the segmented market view, the sector would be called on to create (substandard) positions when job destruction rises in the formal sector and do the reverse in upturns. A voluntary, unregulated micro enterprise view where the sector is generally integrated with the formal salaried sector might suggest patterns of comovement in job creation and destruction. 
To begin, we generate maps of the intensity of worker transitions among labor market states (instantaneous probabilities of movement) which can then be decomposed into the duration of stay in a given state, and the predisposition to move to a different state conditional on separation from the sector of origin. Each statistic offers insight into the nature of the transition process. Looking at average transition matrices for each country, we establish the basic similarities of the labor market dynamics in Argentina, Brazil and Mexico and characterize their relative dynamism by an index of overall "mobility." Second, we examine the patterns of entry into and exit from unemployment, and OLF and extend the analysis to the informal self-employed and salaried sectors. We then examine the Mexican case in more detail, creating a series of instantaneous transition matrices from 1987 to 2002, a period that covers a recovery from recession and boom, the lead up and occurrence of the peso crisis, and then the subsequent recovery.

We find that, as in the US literature, being out of the labor force and unemployed are fundamentally different states. We also find suggestive evidence that, unlike the US, recessions are characterized by reduced job creation, not job destruction. While not conclusive, the stylized facts surrounding the informal sector appear consistent with those emerging from the small firm sector in the US and hence suggestive similarities, despite the differences in sector size. In particular, the sector shares the same patterns of job destruction and creation as the formal sector and in fact contributes more to unemployment than the formal sector and direct flows from the formal sector into the informal sector do not increase during downturns. Further, the self-employed sector behaves as a desirable alternative to formal employment, showing a relative expansion during upturns. However, the informal sectors show much faster rates of job creation than formal employment does meaning that they disproportionately absorb flows from unemployment and hence do expand during downturns.

\section{Methodology}

As Fougère and Kamionka (1992) note, an earlier generation of studies focused on estimating transition probabilities between two periods of time in the context of a 
discrete time Markov chain. ${ }^{2}$ More recent work, including theirs for France and Kalbfleish and Lawless (1985) seek to use discrete panel data to estimate the transition intensities from an underlying continuous Markov process. This has several advantages. First, as pointed out by Singer and Spilerman (1973), the natural time scale for many mobility processes is not a discrete sequence of intervals such as generations or decades but a continuum of time points. Labor status mobility can be viewed more realistically as a process in which states changes occur at random time points, and probabilities of moves between particular states are governed by Markov transition matrices. Secondly, as suggested by Fougère and Kamionka (2003), the analysts has access to individual panel data, which, in general, do not provide observations of continuous labor market histories, and they do not allow to identify directly measures of duration of individual employment and unemployment spells, or the probability to become unemployed at the end of an employment spell.

One way to draw statistical inference of such parameters is to assume that the observed discrete-time mobility process is generated by a continuous-time homogeneous Markov process. We assume a homogenous Markov process $X_{t}$ defined over a discrete state-space $E=\{1, \ldots K\}$ where $K$ is the number of possible states (job sectors) a worker could be found in. The worker if observed at equally distanced points of time. With that information one can construct a discrete time transition matrix $P(t, t+n)$ where

$$
p_{i j}(t, t+n)=\operatorname{Pr}(X(t+n)=j \mid X(t)=i \text { for } t=0,1,2, \ldots, \text { and } n=0,1,2, \ldots,
$$

The interpretation of $p_{i j}$ is simply, the probability of moving from state $i$ to state $j$ in one step $(n)$. Discrete time matrices are easily straight forward to compute as the maximun likelihood estimator for $p_{i j}$ is $p_{i j}=n_{i j} / n_{i}$, being $n_{i j}$ the total number of transitions from state $i$ to state $j$ and $n_{i}$ the total number of observations initially in state $i$. As $n \rightarrow 0$, this gives rise to a $k$ x $k$ transition intensity matrix $Q$ where

\footnotetext{
${ }^{2}$ Notable examples of such estimates of labor market transitions would include Hall (1972), Toikka (1976), Clark and Summers (1979) Akerlof and Main (1980) and Poterba and Summers (1986) for the US. See Hamilton (1994) for a concise explanation of Markov chains.
} 


$$
\frac{d P(t)}{d(t)}=Q P(t)
$$

whose solution is given by:

$$
P(t)=e^{t Q}
$$

where $Q$ is a $k x k$ matrix whose entries satisfy

$$
q_{i j}=\left\{\begin{array}{c}
q_{i j} \in R^{+}, j \neq i, i, j=1, \ldots, K \\
q_{i i}=-\sum_{k=2, k \neq i}^{K} q_{i j} \leq 0, j=i,=i=1, \ldots K
\end{array}\right\}
$$

Thus, $q_{i j}$ elements can be interpreted as the instantaneous rates of transition from state $i$ to state $j$. These must be seen as reduced form estimates combining both the disposition of workers to move to a different state as well as the available "spaces" in that state: a workers desire to take a certain job and the availability of that job, quits and fires etc. As we will see below, this to some degree limits their power to illuminate the forces behind the observed labor force dynamics.

In practice, the estimation of the continuous time transition matrix from is subject to two major difficulties. First of all, solution to equation 2 may not be unique. This is known as the aliasing problem. That is, it is possible for an observed discrete time matrix to have been generated by more than one underlying continuous matrix. On the other hand it is possible that none of the solutions obtained for $Q$ is compatible with the theoretical model expressed in equation 1 where the elements of $Q$ have to satisfy a set of restrictions showed in equation 3. This is known as the embeddability problem. 
Two main approaches have been followed by the literature to estimate the $Q$ matrix and draw statistical inference ${ }^{3}$. Kalbfleisch and Lawless's (1985) maximum likelihood procedure to estimate the elements of $Q$ using a quasi-Newton or scoring algorithm. The main drawback of this approach stems from the fact that if $P$ is not embeddable, then inference using the maximum likelihood is not reliable as standard asymptotic theory does not longer apply ${ }^{4}$.

Geweke et all (1986), propose a Bayesian procedure for statistical inference on intensity matrices as well as any function of the estimated parameters by using a uniform diffuse prior which allows to establish the probability of embeddability of the discretetime matrix. Roughly speaking, the method consists of drawing a large number of discrete time matrices from a previously defined "importance function", assessing their embeddability and constructing confidence intervals of the parameters or functions of interests using only the posterior distribution of those matrices that turn out to be embeddable. This also provides a very natural way of assessing the probability of embeddability as the proportion of the embeddable draws. We have follow this approach, which has also been employed in Fougère and Kamionka (1992 a,b,c)

For interpretational issues, however it is very convenient to decompose the intensity matrix $Q$ into two more manageable indicators: rate of separation and propensity to move. This can be done factorizing the intensity matrix $Q$ as $\lambda(M-I)$ where:

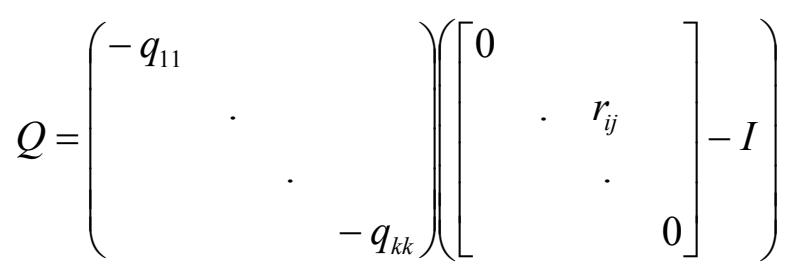

Where elements $r_{i j}=-q_{i j} / q_{i i}$ for $i \neq j$ and $i=1, \ldots, K$ which has the natural interpretation of the probability of a move from state $i$ to state $j$ given separation. This provides measures of transition probabilities conditional on the general rate of turnover in the

\footnotetext{
${ }^{3}$ For an excellent overview of this topic see Fougère and Kamionka (1992a)

${ }^{4}$ The reader is again referred to Fougère and Kamionka (1992a). For an earlier very preliminary paper estimating continuous time matrices for Mexico and Argentina using this technique see Arango and Maloney (2000a).
} 
sector. This can be interpreted as "if all workers were to leave their initial sector at the same rate, what would be the probability of ending in each sector." Broadly speaking, this can be considered a measure of tendency or predisposition. Therefore, throughout the paper we will refer to $r_{i j}$ elements as the propensity matrix. This is especially meaningful when comparing rates of transition for different groups of the populations. For instance, the intensity of transition into sector $j$ from sector $i$ may be higher for group $h$ than for

group $g, q_{i j}{ }^{(h)}>q_{i j}{ }^{(g)}$,but this may only imply that more type $h$ workers leave sector $i$ at any instant than workers type $g$. If we seek to understand the predisposition of a moving worker to enter one sector relative to another, we need to compensate for turnover.

Additional useful inferences can be obtained from estimation of the intensity matrix. For instance, duration times in state $i$ can be shown to be distributed exponentially

$$
d_{i} \sim \exp \left(-q_{i i}\right)
$$

allowing us to retrieve the mean duration time en each sector as

$$
E\left(d_{i}\right)=-q_{i i}^{-1}
$$

Finally, we employ an overall measure of mobility of the intensity matrix to assess the can be computed following Geweke, Marshall and Zarkin (1986) who extend the work of Shorrocks (1978) in the construction of mobility indices in discrete time to continuous time models. This index satisfies a series of desirable properties such as monotonicity, strong immobility, velocity and freedom from aliasing see (Geweke 1986) It takes the form of

$$
M(Q)=-\operatorname{tr}(Q) / K
$$

\section{Data}

In order to construct the time continuous matrices we employ three different surveys which compile information about labor status of workers and other relevant 
information. We employ one year as the time unit to analyze labor mobility dynamics, mainly as a common sampling interval for the three countries.

\section{Mexico}

The Encuesta Nacional de Empleo Urbano (ENEU National Urban Employment Survey) conducts extensive quarterly household interviews in the 16 major metropolitan areas. The questionnaire is extensive in its coverage of participation in the labor market, wages, hours worked, etc. that are traditionally found in such employment surveys. The ENEU is structured so as to track a fifth of each sample across a five quarter period. We have concatenated panels from the first quarter of 1987 to the forth quarter of 1999. For each individual contributed with tow transition pairs (from $1^{\text {st }}$ quarter to the forth and second to the fifth.) giving rise to approximately 1.785 .000 transitions, 810.000 for men and 975.000 for women.

\section{Argentina}

In a similar fashion for Argentina, we use the Encuesta Permanente de Hogares (EPH Permanent Household Survey) a panel covering the area of the Federal District and surroundings (Gran Buenos Aires), which accounts for approximately $60 \%$ of total Argentina employment. The survey is conducted every 6 months (April/May and October) with a $25 \%$ rotation of the panel. As a consequence, each household is followed for two years at sampling intervals of six months. We employ panels from May 1993 to October 2001. The sample is notably smaller than the Mexican and Brazilian surveys and we can only study 29.000 transitions, 13.900 for men and 15.100 for women.

\section{Brazil}

The Pesquisa Mensual do Emprego (PME- Monthly Employment Survey) follows monthly employment indicators. Households are interview four months in a row, reinterviewing them eight moths gap. $25 \%$ of the sample is renewed every month Given this panel structure we can construct four yearly employment status transitions for each individual. We have put together 9 consecutive panels starting in February 1982. Each panel consists of 12 consecutive cohorts covering approximately 2 years covering the 
period 1982-2001. The number of transitions available are 2.520 .000 in total, 1.190 .000 for men and 1.330 .000 for women.

\section{Sectoral Definitions}

We divide the labor force into three sectors of work: formal salaried, informal salaried and self-employed. While the term "informal" suffers from overly broad and imprecise usage, it refers here to owners (Self-Employed) and workers (Informal Salaried) in firms under 16 employees who do not have social security or medical benefits and are therefore not protected. Formal salaried workers are defined as those enjoying labor protections. We drop those falling in the category of unprotected workers in large firms,. The remainder of the sample is divided into two groups those out of the labor force, and the unemployed ${ }^{5}$.

The sample was further divided into two education groups, those with 8 or less years of education (Low Education) and those with more than 8 years (High Education) as well as three age group: less than 24 years of age, 24 to 40 , and then above 40 . We follow Kamionka and Fougere in assuming time homogeneity within each age class but not necessarily across age classes. That is, we hypothesis that if $t$ is the calendar time, and a the age of the individual, $q_{i i}(t, a)=q_{i j}(a)=q_{i j, m}$ where $m$ corresponds to each of our sub-divisions of the sample. Table 1 retrieves the summary of the population distribution among different sectors split according to age and education.

\section{Patterns of Mobility}

We estimate continuous time matrices from the discrete transition data as described above. Table 2 reports the posterior probability of embeddability and suggests that the Brazilian and Mexican matrices are clearly embeddable for all different

\footnotetext{
${ }^{5}$ Unfortunately, the Brazilian survey lacks the information on firm size and informal status is simply given by whether the worker holds a signed work card or not, which guarantees access to benefits in Brazil. Mexican and Argentinean surveys contain very similar questions about benefits and firm sizes.
} 
subgroups. Argentina, however, shows probabilities near unity for the overall matrix and runs into problems when the division of the sample reduces the number of observation.

Tables 3a-c present the estimated $Q$ matrices of intensities-the instantaneous probability of moving from sector $i$ to $j$, and its two component parts, the rate of separation from the each sector, transformed into the mean duration of stay in the sector, and the matrix of propensities to move from $i$ to $j$ conditional on separation from the previous state. The $Q$ matrices suggest that the three labor markets are broadly of the same phylum, showing a high degree of commonality in most any arbitrarily chosen transition. Argentina does differ in some key aspects that seem especially related to the very high rates of unemployment as we discuss below. Hence, were we to study the markets at the same point in the business cycle, even greater commonalities may emerge.

Going deeper and breaking apart the transition probabilities into turnover and propensity matrices, a number of common features strongly emerge from the three datasets which we now discuss.

\section{a. Labor Market Mobility/Flexibility}

The rate of turnover has been used as one benchmark of labor market flexibility (see for example Nickell 1997). The overall mobility of workers through the matrix may thus provide a more comprehensive measure. Table 4 presents the Geweke, Marshall and Zarkin (1986) mobility index for the three countries, by country, gender age and educational group. Argentina emerges as the country with the least mobility for all groups with Mexico and Brazil more or less similar to each other, Mexico only slightly more mobile in most of the subgroups. Since higher education or age may lead to higher levels of firm specific capital and attachment, we present the indexes disaggregated by both with age and education to see if the overall index is simply reflecting Argentina's more educated and older population. The Argentine matrix still appears "slower" even controlling for these demographic characteristics. 
Since the mobility index is, effectively, the average mobility across all sectors, it may be that the results are being driven by one extreme sector. Figure 1 plots the absolute mean duration of stay in each sector. Again, as with the intensity matrices discussed above, the similarities are far more striking than the differences. Particularly notable are the common patterns of relative durations across countries: shortest in unemployment followed by informal salaried, self-employment or out of the labor force and then longest in formal salaried employment. But differences there are. Brazil shows higher durations than Argentina in self- employment, informal salaried work and OLF, and Mexico shows higher durations in self-employment. As is perhaps expected given its history of energetic unions and restrictive labor codes, Argentina shows high durations in the formal sector. However, the fact that Brazil has only slightly lower formal sector durations makes the stylized impression of the Argentine market as especially overregulated perhaps harder to sustain. In fact, what the mobility index appears to be picking up is the influence of the very depressed labor market across this period that have led to a far higher duration of stay in unemployment before finding another job than in the other countries.

\section{b. Transitions Among Sectors}

\section{OLF and Unemployment}

The propensity matrices cast suggest that, similar to the US, OLF has more complex function than simply discouraged unemployment. In both Mexico and Brazil, workers are more likely to move directly from OLF into employment than to pass through a period of search in unemployment. The reverse movements tell something of a mixed story for men. Transitions into OLF from work are low- under 15\%- and for Argentina and Mexico, propensities from unemployment are perhaps double that suggesting a flow of discouraged workers. On the other hand, the unemployed in Brazil unemployment show a lower propensity than most paid sectors to be a source of flows into OLF. Thus, the male transitions offer a murky story on the role of the sector and firmer conclusions must for the more convincing evidence from business cycle analysis. However, two very striking facts emerge which merit attention. 
First, in striking contrast to the men, in Mexico and Brazil, the propensity of women to move from self employment to OLF is very high, .69 and .73 percent respectively (over four times higher than for males), and the reverse flows are higher than to any sector of work. On average, women show far longer spells in OLF than men: twice as long in Mexico, 45\% longer in Brazil, and 25\% more in Argentina and shorter spells in self-employment 55\% less in Brazil, $47 \%$ less in Mexico and 38\% less in Argentina. The rapid transitions between these two sectors largely explains the fact the higher mobility indexes for women than for men. Finally, women show a lower propensity to transit to the self-employment sector from the formal, and informal sectors and unemployment. There is clearly a particular relationship between self-employment and OLF. We return to both observations in the next sections.

Second, Argentina appears to present a special case where almost $65 \%$ of men leaving OLF go into unemployment, a number triple the other countries for both genders. This suggests that the pattern of entry into work is substantially different than for the other countries.

\section{Self Employment}

Figure 4 suggest that the informal self-employed behave quite similarly their first world colleagues and rather less like those in a queue for good formal sector jobs. Evans and Jovanovic argued that the observed increasing probability of entry with age, despite a presumably lower level of risk aversion among the young, was consistent with the existence of credit constraints. Strikingly consistent with this view, in all three countries the probability of entry for young workers from OLF or unemployment is a mere fraction of that for older workers. This, the largest segment of informality in most countries (see table 1), is not a port of entry into work. Less than $10 \%$ of young workers (16-24) leaving the OLF sector and unemployment choose self-employment as their entry point in the labor market, around 3 times less than the next age segment (24-40). Further, the propensity to enter the sector from informal or formal salaried work is also, in all cases, often over double for older workers than for younger workers. For instance, 35\% (20\%) 
of younger Mexican workers leaving the informal (formal) salaried sector start a business compared with the $57 \%$ (44\%) of their immediately older counterparts. Similar results are found in Argentina and Brazil where roughly 20\% (10\%) of exiting young informal (formal) workers find a self-employment opportunity compared to $40 \%(20 \%)$ of older workers self-employment. Generally speaking, the transition patterns are consistent with a life cycle model where, in an environment of weak education systems and credit markets, workers may enter formal employment to accumulate both human and financial capital, and then open their business

Figure 3 also suggests that older and better educated workers spend longer spells in self-employment. This would be consistent with the mainstream firm dynamics literature that suggests that young firms, which, ceteris paribus are more likely to be opened by young workers, have very high failure rates (see Jovanovic 1982 and Evans and Leighton 1989). The pattern of tenure increasing for more educated workers is similar to that found in the formal sector and the opposite of that found in the informal salaried sector for informal workers.

It may be argued that both the pattern of late entry and longer duration with age are also consistent with the idea that after middle age, a worker who loses his formal sector job will not be able to find a new one and hence is forced into self employment. But two features of the matrices mitigate against this view as being the entire or even a large part of the story. First, the rate of transition into the sector in all three countries seems broadly linear in age up until middle age. That is we do not see a sudden spike in propensities among old workers, but rather a gradual increase with something of a inflection point at prime age, when the propensity to enter often begins to decrease. This patterns seems more consistent with a prime age worker having accumulated sufficient human and physical capital than with the older workers being less and less likely to access the formal sector market once fired.

Both the sociological literature and economic data offers reasons why poorer workers might prefer self employment over salaried work. In both Mexico and Brazil, 
motivation questions attached to the surveys used here reveal a preference for independence and higher levels of income among entrants consistent with Blanchflower and Oswald's (1998) findings for the US, UK and Germany. ${ }^{6}$ The flexibility afforded by self employment may also explain the especially dynamic corridor between self employment and self-employment found among women. In a view with lineage to Becker's (1991) work stressing structural determinants of employment patterns, Cunningham (1996) argues that Mexican womens' patterns of participation, and particularly their gravitation toward self employment are driven by their need to balance their other responsibilities in the household: child raising requires a greater job flexibility than the salaried sectors offers.

If this were the case, rather than an alternate model that women are discriminated against and hence are forced into informality, then we might expect that single women would show similar mobility patterns to men. Table 6 extracts a cohort of single women for the two surveys with a marital status variable, Argentina and Mexico. The intensity matrices of single women now have become very similar to those of men and this similarity holds up when disaggregated by duration and propensity. Most of the difference in OLF duration can be explained by marital status. In fact Argentine single women now spend less time OLF than men do. Similarly, Mexican single women spend 3.13 years in OLF instead of 5.1 for their gender overall, far closer to the mean spell of men, 2.57. We also now find that the propensities to transition into OLF from every sector are also significantly reduced and that transitions from OLF into self-employment are equal or slightly below men for both countries. In other dimensions, single women appear to have largely standard male labor market patterns. In both countries, they appear to enter from OLF into search and directly into formal salaried employment at the same rates as men and from unemployment they enter with propensities as high or higher than men. It seems plausible that the exaggerated OLF-self-employment dynamic is

\footnotetext{
${ }^{6}$ In Mexico, a linkable micro enterprise survey reveals that around two-thirdsof workers entering self employment from the formal salaried sector cited either more flexibility or higher earnings as the reasons. The Brazilian survey use here, over $62 \%$ of self-employed workest stated that they did not want a formal sector position, primarily because they were happy with their current job.
} 
largely driven by periodic child bearing related shocks and the subsequent need for flexibility to manage family responsibilities.

In sum, the dynamics of the sector are broadly consistent with those found for the US and are plausibly consistent with a large fraction of the sector entering voluntarily.

\section{Informal salaried}

Informal salaried workers are often seen as the more disadvantaged workers in LDC labor markets. Table 2 and Figure 2 suggests however, that sector is very particular in heavily weighted toward the young. We find, that, in contrast to self employment, entry into the sector decreases with age from either unemployment or OLF suggesting that it may, in fact, be a port of entry into the labor force.

The very high propensities for Argentine workers to enter unemployment from OLF rather than enter directly into work and, in the Brazilian case, especially informal salaried work raises the question of why, in an economy of high unemployment, the informal sector is not absorbing unemployed workers as Harris and Todaro imagined. One possibility suggested by Maloney and Nuñez (2003), is that some formal sector rigidities, in particular the minimum wage, are very binding even or especially in the informal sector in Argentina and hence the market cannot clear there either. Again, the breakdown by skill level does not suggest that this is due to Argentina's more skilled work force preferring unemployment to a poor job match in the informal sector.

More generally, the informal sectors seem to contribute as much to unemployment as being a substitute for it. If informality were the refuge for displaced workers who could not afford to be unemployed, we might expect few transitions between the two states-that is they would behave more like substitutes and one would leave formal sector employment into one or the other. But in all three countries, a very strong tendency exists for the informal self-employed and informal salaried to transit into unemployment. Table 5 shows a breakdown of the new unemployed by sector of origin 
computed using original sector sizes and the estimated intensities to calculate flows. Surprisingly a large proportion of the unemployed actually were previously employed in the informal sectors (40\% in Brazil and 50\% in Mexico). This is especially acute in Argentina where unemployment hovered at $20 \%$ in recent years. Overall, $60 \%$ of job destruction had its origin in the informal sector. This is very consistent with the finding in the industrialized countries that micro firms have very high rates of failure, and hence failed entrepreneurs and their informal salaried employees are likely to find themselves frequently unemployed. It is far less consistent with the sector being comprised of separated workers who cannot afford to be unemployed and who search for new jobs from the informal sector.

More generally, the story is consistent across all three countries that informal salaried workers do not spend long in these jobs--durations are just over a year. Further, Figure 3 suggests that durations decrease with age and education in Mexico and Argentina. This may reflect that young workers receive training in the sector, or are helping out their parents who frequently are the owner of the micro firm. Later in life, the sector may serve more as a way-station to another job with attendant lower stays. Perhaps for the data considerations discussed earlier Brazil behaves differently, showing a leveling off at a higher level in middle age.

\section{Dynamics over the Business Cycle.}

Further insights into the role each sector plays can be extracted from the generating a series of transition matrices across time and following the adjustment process of the market across the business cycle. In this section we examine the Mexican market from 1987-2001, a period that includes the celebrated peso crisis of 1995. Figure 5 first presents an overview of the variation of the share of the work force in unemployment, formality and informality. The evolution of the unemployment rate (the bar in figure 5) corresponds to the stylized facts about the macroeconomic evolution across the period. 
Period 1 Recovery: Recovering from a recession at the end of the late 80's, through the first years of the 1990, the unemployment rate declines to the very low $3 \%$ and hovers there until the beginning of 1992.

Period 2: Appreciation of the peso, economic slow down and crisis: The two years prior to the Peso crisis saw a slow but continuous increase in the unemployment rate. This culminated in the sudden spike to a decade high of $8 \%$ during the $2^{\text {nd }}$ quarter of 1995 in the midst of the crisis.

Period 3: Recovery: A large devaluation of the peso and a strikingly rapid recovery of the economy returned the unemployment rate to its pre-crisis levels in a matter of months.

\section{a. Movements in employment shares.}

We begin looking first at the evolution of each sectors' share of the labor market across the two recoveries and crises. We use unemployment rates to help define broad periods of recovery and recession above. What deserves mention immediately is that despite the magnitude of the 1995 shock, the unemployment rate remained in the single digits and showed an extremely rapid recovery. This is partly due to a $25 \%$ fall in the real wage engineered by holding nominal wages fixed and allowing the devaluationinduced inflation to erode real magnitudes. That said, the adjustments in prices were nowhere near sufficient to eliminate movements in quantities and these are manifest in the significant reallocation of workers across sectors.

The share of the formal sector remained reasonably constant from 1987 to 1992 at around $53 \%$ of the labor force. Thereafter, however, it began a slide to $48 \%$ on the eve of the crisis before bottoming out at $45 \%$. After the devaluation, it began a sharp recovery, almost regaining its earlier highs by 2001 . These movements are largely mirrored by the movement of unemployment from 3\% in 1989 to $8 \%$ during the crisis and then again down to the lowest levels in the sample in 2001. Consistent with Diamond and 
Blanchard, OLF is clearly not simply discouraged unemployment since it moves opposite to unemployment in a strongly procyclical way, falling from $19 \%$ of the workforce to $15 \%$ during the crisis before partially recovering to $17 \%$ in 2000 . In sum, the rise in unemployment could be accounted for easily by either the shift of workers from OLF into search, or the decrease in formal employment, but would be exceeded by the combination of both tendencies. The informal sectors clearly play an important role in the adjustment.

However, the movements in the informal sectors fit somewhat uncomfortably in a view of residual or disguised unemployment. The sector saw a modest increase to $44 \%$ during the boom of the first period as unemployment fell-- like OLF, it behaves procyclically, most of the movement being driven by self employment. However, coinciding with the increase in unemployment rates starting in 1993, it shifts to behaving counter cyclically and the sector expands to $46 \%$ on the eve of the crisis and then to $48 \%$ during the crisis, surpassing formal sector employment as the largest generator of employment. The subsequent recovery of the economy was characterized by a similarly remarkable role reversal and by the end of 2001 relative shares almost at their 1989 levels.

In sum, the crisis period suggests a very traditional view of the behavior of the role of the informal sector as a shock absorber for the formal sector and perhaps a kind of disguised unemployment. However, the procyclical movement in self employment's share in the 1989-1991, and 1999-2001 recoveries suggests an important missing part of the story. Further, we have no clear view of exactly how the workforce was reallocated among sectors and in particular whether the rise in the non formal sectors is due to job destruction in the formal sector or lack of job creation that left workers with nowhere to go. Both issues are illuminated by looking into the patterns of transition among sectors.

\section{b. Duration over the business cycle}

As discussed in the previous section, the probability of movement from one sector to another can be broken down into average rates of turnover or rate of separation from a particular sector and then its propensity, conditional on that turnover, to move into that 
sector. We begin looking at the overall level of mobility in the labor market across the business cycle.

Theory is ambiguous on what patterns of duration we may see across the business cycle. A view of a downturn as a negative shock to the formal sector in the presence of wage rigidities may suggest a decline in duration during crises. Symmetrically, if informal sector workers are effectively like disguised unemployed, rationed out of desired formal sector employment, we may expect duration in unemployment and informality to lengthen during recessions as the possibilities of transition to formal sector jobs decrease and queuing time increases. On the other hand, if we consider informal employment as simply another alternative to formal employment, but one that is perhaps risky or plagued by credit restrictions, then we may be in a world closer to the quitting function literature (Bulow and Summers 1986, Phelps 1968, Salop 1979, Phelps and Hoon 1992). Here, the increased opportunities in the alternate sector, or the greater likelihood of regaining a position in the formal sector in the event of business failure could lead to pro-cyclical quit rates out of formality accompanying more turnover in the informal sector as well. Duration in OLF also depends some on whether it is considered discouraged unemployment, or voluntary idleness.

Figure 6 suggests that duration in the formal sector is, in fact, strongly counter cyclical. The recoveries in 1987-90 and 1997-2000, marked by decreasing unemployment and good macroeconomic conditions, saw significant decreases in duration in the formal sector. Apart from the quarters immediately prior to the tequila crisis and the impact of the crisis itself the hazard rate of the formal sector decreased throughout the 90's (duration increased).

Strikingly, the evolution of duration of both the informal sectors is very similar to those of the formal sector (Figure 6) suggesting that the factors determining turnover (i.e: macroeconomic conditions dictating quitting or firing) affect all of them in a similar fashion. Figure 7 suggests that duration in unemployment again is highly procyclical reflecting the ease of finding jobs during upturns. Duration in OLF is generally acyclical 
although it decreases sharply during the crisis. This likely reflects the increase in search which manifests itself in the reduction in the size of the OLF sector and increase in the size of the unemployed sector. Generally speaking, there is increased mobility throughout the matrix in recoveries, and a slowdown during recessions. In the particular case of formal salaried work, the falling share of employment in formal salaried employment concomitant with this decreasing turnover suggests that the recession and subsequent crisis were characterized less by job destruction, than a decline in job creation.

\section{c. Intersectoral Flows}

\section{Unemployment and Out of the Labor Force}

Paralleling the mainstream literature, we first follow the transitions between formal salaried employment and the two sectors of non employment: unemployment and out of the labor force. Figure 10 confirms our earlier intuition about the adjustment in the formal sector. Transitions from the formal sector into unemployment rise after the initial recovery period, but then are fairly stable leading up to the crisis where they spike dramatically, but then fall immediately after to traditional levels. The major action, however, is in accessions to the sector from unemployment. These slow down dramatically leading up to, bottom out during, and rapidly recover after, the crisis.

As Flinn and Heckman (1982) concluded for the US, OLF has behavior clearly distinct from that of unemployment. Movements between FS and OLF are highly symmetric and probabilities increase procyclically: workers do not enter OLF during recession and hence the sector is unlikely to be serving as discouraged unemployment. In fact, since OLF turnover is largely acyclical, the movements are largely driven by changes in propensities: a given separation from the formal sector is less likely to lead to a movement to OLF in recession and the same is true for the reverse transition. 


\section{Formality-Informality}

What is striking is how much more similar transitions between the formal and informal sectors are to OLF, than to unemployment. Figure 8 shows that, as expected, we observe pro-cyclical transitions from informality to formality. However, again we find virtually and strikingly identical pro-cyclical transitions from formality to both informal sectors. Also striking, but perhaps not surprising given the symmetry, is that most of movement in probabilities is driven by the overall level of mobility through the matrix and not generally to changes in specific changes in propensities to move among sectors, conditional on turnover (figure 9). In the lead up to the crisis, propensities to move from formal to informal salaried work are largely constant across the period and those to self-employment show something of a return to mean after being unusually high during the boom of the early 1990s, and then a brief spike around the crisis. However, again, the movements are relatively subtle relative to the movements in the overall probabilities. By contrast, there are very large movements of the propensities to move to unemployment from .13 to .3 and a decline into OLF from .15 to .5 . Taken together, this implies that the key movements during the recession were emphatically not into the informal sector, but into unemployment.

The view from self employment shows somewhat more variation, but still strikingly similar patterns. There is an unusually high propensity of movement into formal employment during the boom of the first phase that mirrors the reverse movement from the formal sector. This suggests that there was a particularly strong re-matching between these two sector during that recovery. There is something of a decline going into the crisis and then a recovery again mirrored, although more weakly, in the reverse transition. The largest offsetting movement in propensities is into unemployment, moving from .1 in 1989 to almost .2 on the eve of the crisis and then spiking at almost 3 during the crisis.

The informal salaried sector shows a similar pattern of declining propensity to enter formal work that is largely offset by an increase to unemployment of only slightly lower magnitudes compared to the other two sectors, and a secular increase to self 
employment. This secular increase is matched by a secular decrease in movement into formal employment and is matched by a complementary increase from self-employment into informal salaried work.

The overall similarities in the behavior of patterns of job destruction among the three employment sectors are suggest in the transition probabilities to unemployment and self-employment plotted in figure 11. In every case, movements into OLF follow the same procyclical pattern and movements into unemployment the same, although in some cases noisier, counter cyclical pattern. In sum, there is not evidence from either the Q or $\mathrm{R}$ matrices that the informal sector directly absorbed those displaced from the formal sector. Consistent with the findings from the static picture of the previous sector, they contribute substantially to the increase in flows into unemployment. In fact, the probability of moving into unemployment during the crisis is just below .05 from the formal sector, .08 from self employment and .17 from informal salaried work. Job destruction was largest in the informal sector and accounts for the largest flows into unemployment during the crisis.

The expansion of the self-employed sector, then is driven by two facts, both related to the lower hiring rates in the formal sector. Direct movements to the formal sector from the other two is asymmetrically lower, as shown by the propensity matrices. Further, those who become unemployed had progressively lower propensities to enter formal employment, progressively higher access into informal salaried and a similar but less pronounced trend into self employment. The story of the period leading up to the crisis is one of disproportionately decreased access to the formal sector rather than job destruction.

\section{Conclusion}

This paper has sought to generate some stylized facts about LDC labor markets using a common methodology across three sets of panel data. We estimate continuous time Markov processes for workers transitioning across three employment states, 
unemployment, and being out of the labor force. Calculating intensities of movements (instantaneous probabilities), duration of stay, and propensities to transit among sectors conditional on separation, we first note a high degree of similarity among the three countries with Argentina's very high unemployment rate likely to account for much of the difference.

We then compare rates of mobility as a potential measure of labor market flexibility. As is the case in the stylized notions of the market, Argentina appears more rigid that the other two, even when controlling for important differences in the age and education of the work force. However, disaggregating by sector suggests that formal sector turnover rates are roughly equal to those of Brazil and the apparent low mobility appears mostly due to much longer spells in unemployment.

We then parallel the mainstream literature in focusing on the roles played by the distinct sectors. We begin with the standard question about whether being out of the labor force is really discouraged unemployment or something distinct and then move on to a related although perhaps more relevant question in LDCs: the role of the large informal sector that is largely absent in the advanced. The overarching query is whether these should be treated as also as disguised unemployment or, again as something different, in this case the something different being more of an unregulated microfirm sector. The matrices suggest a kinship of this sector to that described in the US where entrants into the sector may be constrained in their accumulation of human and physical capital. Consistent with the US literature, those entering the sector are older (but not the oldest), and those working for them are among the youngest and most transitory. The high mortality rates found in any small firm sector may explain why the two informal sectors to flows into unemployment than the formal sector.

We then study the patterns of transitions across a complete business cycle in Mexico that includes the celebrated peso crisis of 1995. We find, first, that transitions among the three employed sectors and being out of the labor force are all highly symmetrical and procyclical. The most dramatic evolution across the cycles is the 
counter cyclical and very similar movement of turnover in all sectors. An essential finding is that in both recoveries, and in particular, that from 1987-91, flows between the formal salaried and self-employed sectors expanded greatly and in favor of informal self employment yielding procyclical movements that are in contradiction to standard dualistic views of the sector.

Where the patterns are more consistent with these views is in the lead up to the crisis and the crisis itself, although in a very particular way. Job destruction was, in fact, highest in the informal sector and there is little evidence that the sector was directly absorbing displaced workers from the formal sector. However, what accounts for an expansion of self employment across the period is that access to formal employment from both the other paid sectors and unemployment declined, leaving the informal sector to pick up the slack.

As in the mainstream literature, being out of the labor force emerges as playing a distinct role from unemployment and we conjecture the outsized self employment sector is just that- analogous but larger. Overall, the comovements of turnover and symmetries of movements suggest sectors that are relatively well integrated and not fundamentally distinct as desirable sources of employment, although the informal sectors do take up more slack in downturns. 


\section{References}

Arango, Carlos. and William F. Maloney (2000) "Unemployment Dynamics in Latin America: Estimates of Time Markov Models for Mexico and Argentina" mimeo IBRD.

Becker, Gary (1991) A Treatise on the Family(Enlarged Edition.) Cambridge MA: Harvard University Press.

Blanchflower, D.G. and A.J. Oswald (1998) "What Makes an Entrepreneur? Journal of Labor Economics 16 (1) 26-60.

Bulow, Jereamy and Lawrence Summers (1986) "A Theory of dual Labor markets with Application to Industiral Policy, Discrimination and Keynesian Unempoyment" Journal of Labor Economics 4:376-414.

Cunningham, Wendy (1996) Breadwinner vs. Caregiver: Labor Force Participation and Sectoral Choice over the Mexican Business Cycle" in Elizabeth G. Katz and Maria C. Correia eds., The Economics of Gender in Mexico: Work, Family, State and Market, The World Bank, Washington, D.C.

Hamilton, James D. (1994), Time Series Analysis, Princeton University Press, New Jersey: Princeton.

Harris, J.R. and M.P. Todaro (1970) "Migration, Unemployment and Development: A Two Sector Analysis." American Economic Review 60 (1) 126-42.

Hart, Keith (1972), Employment, Income and Inequality: A Strategy for Increasing Productive Employment in Kenya, Geneva: ILO

Hoon, H and Edwin Phelps (1992) "Macroeconomic Shocks in a dynamized Model of the Natural Rate of unemployment” American Economic Review, 82:889-900

Inter-American Development Bank (2004). "Good Jobs Wanted: Labor Markets in Latin America. Economic and Social Progress Report. Washington D.C.

Denis Fougère and Thierry Kamionka (2003), Bayesian Inference for the Mover-Stayer Model in Continuous Time with an Application to Labour Market Transition Data. Forthcoming in Journal of Econometrics.

Denis Fougère and Thierry Kamionka (1992a) Individual Labour Market Transitions in Laslo Matyas and Patrick Sevestre The Econometrics of Panel Data: A Handbook of the Theory with Applications. Kluwer, Boston ch 29.

Denis Fougère and Thierry Kamionka (1992b), Mobilité et Précarisation sur le Marché Français du Travail: Une Analyse Longitudinale Pour les Années 1986-1988. Economie et Prevision, 102-103: 157-178. 
Denis Fougère and Thierry Kamionka (1992c), Un Modele Markovien du Marché du Travail," Annales d'Economie et de Statistique, 27:501-8.

Maloney, William F. and Jairo Nuñez (forthcoming) "Measuring the Impact of Minimum Wages" in J.Heckman and C. Pages eds. Law and Labor Markets: Lessons from Latin America, National Bureau of Economic Research and University of Chicago Press, Also NBER working paper 9800.

Maloney, William F. (1999) "Does Informality Imply Segmentation in Urban Labor Markets? Evidence from Sectoral Transitions in Mexico," World Bank Economic Review 13:275-302.

Nickell, Stephen. (1995). "Labour Market Dynamics in OECD Countries.” Discussion Paper 255. Centre for Economic Performance, The London School of Economics and Political Science, London.

Nickell, Stephen. (1997). "Unemployment and Market Rigidities: Europe versus North America." Journal of Economic Perspectives 11(3):5-74.

Phelps, E (1994) Structural Slumps: The Modern Theory of Unemployment, Interest and Assets, Cambridge MA: Harvard University Press.

Salop, S. (1979) "A Model of the Natural Rate of Unemployment" American Economic Review 69:117-25.

Stiglitz, Joseph E. (1974) 'Alternative Theories of Wage Determination and Unemployment in LDC's: The Labor Turnover Model” The Quarterly Journal of Economics 88(2): 194-227. 
Table 1: Sample Distribution Among Sectors for Different Age and Education Groups.

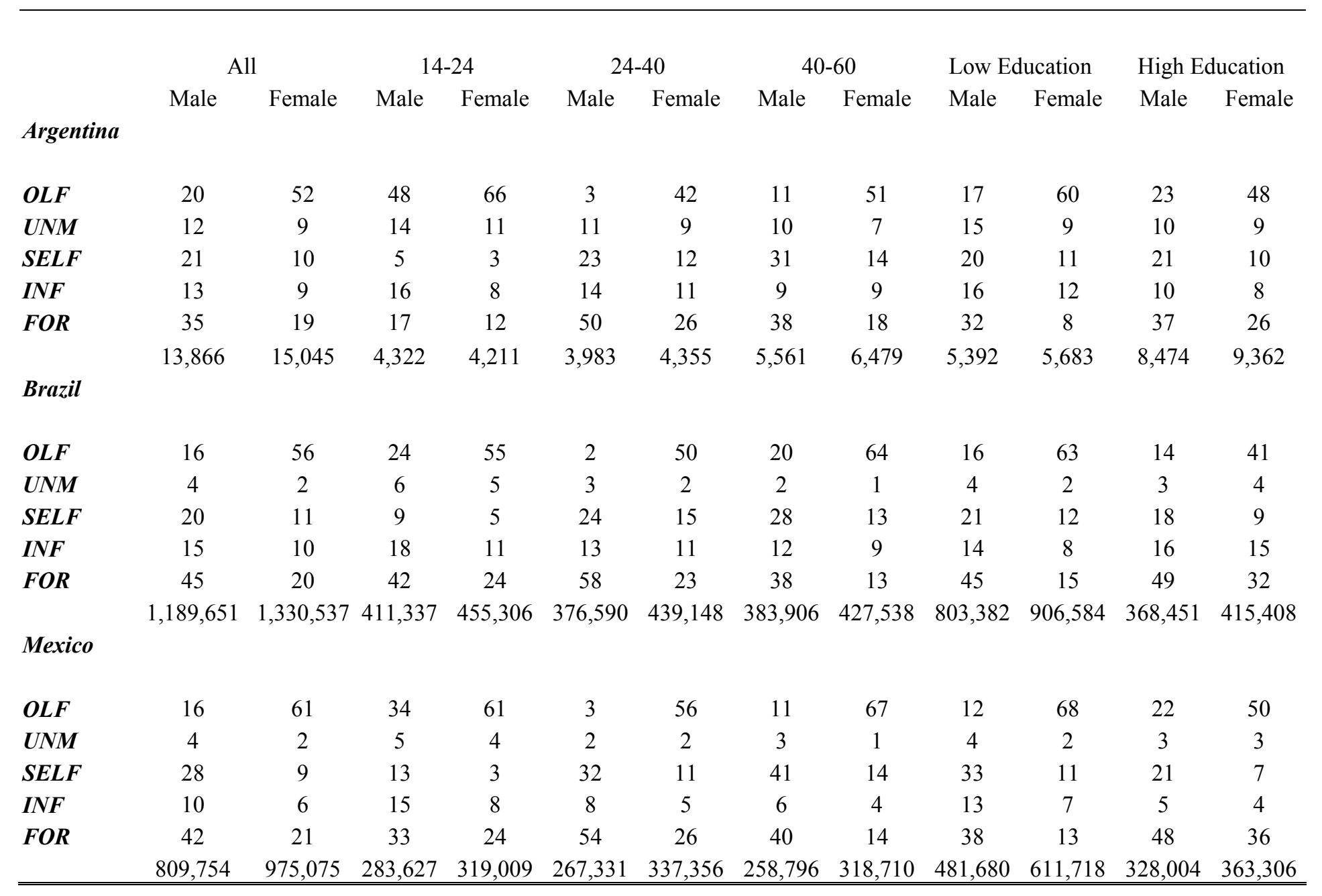


Table 2: Posterior Probability of Embeddability Indexes various Ages.

\begin{tabular}{lcccccc}
\hline & \multicolumn{2}{c}{ Argentina } & \multicolumn{2}{c}{ Brazil } & \multicolumn{2}{c}{ Mexico } \\
& Male & Female & Male & Female & Male & Female \\
& & & & & & \\
All & 0.97 & 1.00 & 1.00 & 1.00 & 1.00 & 1.00 \\
$\mathbf{1 4 - 2 4}$ & 0.78 & 0.82 & 1.00 & 1.00 & 1.00 & 1.00 \\
$\mathbf{2 4 - 4 0}$ & 0.38 & 0.91 & 1.00 & 1.00 & 1.00 & 1.00 \\
$\mathbf{4 0 - 6 0}$ & 0.68 & 1.00 & 1.00 & 1.00 & 1.00 & 1.00 \\
Low Education & 0.20 & 0.51 & 1.00 & 1.00 & 1.00 & 1.00 \\
High Education & 0.54 & 1.00 & 1.00 & 1.00 & 1.00 & 1.00 \\
\hline \hline
\end{tabular}

Computations are based on 10.000 Monte Carlo draws 
Table 3a: Intensity Matrix, Duration and Propensity Matrix: Argentina

\begin{tabular}{|c|c|c|c|c|c|c|c|c|c|c|}
\hline \multicolumn{2}{|c|}{ Intensity Matrix } & \multicolumn{4}{|c|}{ Males } & \multicolumn{5}{|c|}{ Females } \\
\hline & $O L F$ & $U N M$ & $S E L F$ & $I N F$ & FOR & $O L F$ & $U N M$ & $S E L F$ & $I N F$ & FOR \\
\hline \multirow[t]{2}{*}{$O L F$} & -0.3411 & 0.2274 & 0.0101 & 0.0748 & 0.0287 & -0.2718 & 0.1723 & 0.0427 & 0.0412 & 0.0155 \\
\hline & 0.0119 & 0.0128 & 0.0048 & 0.0089 & 0.0048 & 0.0065 & 0.0069 & 0.0031 & 0.0041 & 0.0020 \\
\hline \multirow[t]{2}{*}{$U N M$} & 0.2162 & -1.0844 & 0.2811 & 0.4086 & 0.1784 & 0.6866 & -1.2904 & 0.1141 & 0.3553 & 0.1343 \\
\hline & 0.0158 & 0.0358 & 0.0191 & 0.0267 & 0.0145 & 0.0322 & 0.0446 & 0.0172 & 0.0275 & 0.0136 \\
\hline \multirow[t]{2}{*}{ SELF } & 0.0329 & 0.1519 & -0.3772 & 0.1486 & 0.0439 & 0.2369 & 0.0997 & -0.6248 & 0.2557 & 0.0325 \\
\hline & 0.0046 & 0.0099 & 0.0113 & 0.0097 & 0.0050 & 0.0158 & 0.0155 & 0.0223 & 0.0186 & 0.0062 \\
\hline \multirow[t]{2}{*}{$I N F$} & 0.0577 & 0.3515 & 0.2876 & -0.8779 & 0.1810 & 0.2356 & 0.3190 & 0.2755 & -0.9174 & 0.0873 \\
\hline & 0.0095 & 0.0237 & 0.0177 & 0.0281 & 0.0130 & 0.0216 & 0.0261 & 0.0191 & 0.0315 & 0.0101 \\
\hline \multirow[t]{2}{*}{ FOR } & 0.0072 & 0.0920 & 0.0272 & 0.0533 & -0.1797 & 0.0247 & 0.0684 & 0.0224 & 0.0381 & -0.1537 \\
\hline & 0.0020 & 0.0061 & 0.0032 & 0.0044 & 0.0056 & 0.0042 & 0.0066 & 0.0034 & 0.0049 & 0.0068 \\
\hline \multicolumn{11}{|c|}{ Duration } \\
\hline & $O L F$ & $U N M$ & $S E L F$ & $I N F$ & $F O R$ & $O L F$ & $U N M$ & $S E L F$ & $I N F$ & $F O R$ \\
\hline & 2.9356 & 0.9232 & 2.6534 & 1.1403 & 5.5709 & 3.6818 & 0.7759 & 1.6026 & 1.0913 & 6.5208 \\
\hline & 0.1024 & 0.0302 & 0.0796 & 0.0365 & 0.1736 & 0.0881 & 0.0267 & 0.0573 & 0.0376 & 0.2906 \\
\hline \multicolumn{11}{|c|}{ Propensity Matrix } \\
\hline & $O L F$ & $U N M$ & $S E L F$ & $I N F$ & $F O R$ & $O L F$ & $U N M$ & $S E L F$ & $I N F$ & $F O R$ \\
\hline \multirow[t]{2}{*}{$O L F$} & & 0.6666 & 0.0297 & 0.2194 & 0.0843 & & 0.6339 & 0.1573 & 0.1517 & 0.0572 \\
\hline & & 0.0282 & 0.0141 & 0.0249 & 0.0139 & & 0.0174 & 0.0112 & 0.0151 & 0.0073 \\
\hline \multirow[t]{2}{*}{$U N M$} & 0.1994 & & 0.2593 & 0.3768 & 0.1645 & 0.5321 & & 0.0885 & 0.2753 & 0.1041 \\
\hline & 0.0129 & & 0.0161 & 0.0197 & 0.0128 & 0.0172 & & 0.0133 & 0.0181 & 0.0101 \\
\hline \multirow[t]{2}{*}{ SELF } & 0.0872 & 0.4026 & & 0.3939 & 0.1164 & 0.3792 & 0.1597 & & 0.4091 & 0.0520 \\
\hline & 0.0121 & 0.0231 & & 0.0222 & 0.0130 & 0.0220 & 0.0244 & & 0.0247 & 0.0098 \\
\hline \multirow[t]{2}{*}{$I N F$} & 0.0658 & 0.4003 & 0.3277 & & 0.2063 & 0.2569 & 0.3476 & 0.3003 & & 0.0952 \\
\hline & 0.0108 & 0.0218 & 0.0179 & & 0.0140 & 0.0225 & 0.0248 & 0.0178 & & 0.0107 \\
\hline \multirow[t]{2}{*}{ FOR } & 0.0400 & 0.5119 & 0.1516 & 0.2965 & & 0.1610 & 0.4453 & 0.1456 & 0.2481 & \\
\hline & 0.0111 & 0.0282 & 0.0176 & 0.0235 & & 0.0266 & 0.0374 & 0.0212 & 0.0299 & \\
\hline
\end{tabular}

Standard Errors in italics below. Computations are based on 10.000 Monte Carlo draws 
Table 3b: Intensity Matrix, Duration and Propensity Matrix: Brazil

\begin{tabular}{|c|c|c|c|c|c|c|c|c|c|c|}
\hline \multicolumn{3}{|c|}{ Intensity Matrix } & \multicolumn{3}{|l|}{ Males } & \multicolumn{5}{|c|}{ Females } \\
\hline & $O L F$ & $U N M$ & $S E L F$ & $I N F$ & FOR & $O L F$ & $U N M$ & $S E L F$ & $I N F$ & FOR \\
\hline \multirow[t]{2}{*}{$O L F$} & -0.2823 & 0.0670 & 0.0402 & 0.1223 & 0.0528 & -0.1938 & 0.0406 & 0.0743 & 0.0484 & 0.0304 \\
\hline & 0.0014 & 0.0011 & 0.0007 & 0.0011 & 0.0010 & 0.0007 & 0.0005 & 0.0004 & 0.0004 & 0.0003 \\
\hline \multirow[t]{2}{*}{$U N M$} & 0.1855 & -1.9475 & 0.3217 & 0.5413 & 0.8992 & 0.8444 & -2.0680 & 0.1519 & 0.4055 & 0.6662 \\
\hline & 0.0043 & 0.0135 & 0.0054 & 0.0082 & 0.0089 & 0.0100 & 0.0160 & 0.0054 & 0.0086 & 0.0091 \\
\hline \multirow[t]{2}{*}{$S E L F$} & 0.0426 & 0.0397 & -0.2900 & 0.1324 & 0.0752 & 0.4112 & 0.0148 & -0.5923 & 0.1234 & 0.0428 \\
\hline & 0.0006 & 0.0009 & 0.0012 & 0.0011 & 0.0008 & 0.0022 & 0.0010 & 0.0025 & 0.0014 & 0.0010 \\
\hline \multirow[t]{2}{*}{$I N F$} & 0.0904 & 0.1065 & 0.1941 & -0.7252 & 0.3342 & 0.2000 & 0.0705 & 0.1286 & -0.7201 & 0.3210 \\
\hline & 0.0011 & 0.0018 & 0.0015 & 0.0027 & 0.0021 & 0.0018 & 0.0019 & 0.0015 & 0.0030 & 0.0021 \\
\hline \multirow[t]{2}{*}{ FOR } & 0.0219 & 0.0832 & 0.0471 & 0.0889 & -0.2411 & 0.0730 & 0.0733 & 0.0207 & 0.1305 & -0.2976 \\
\hline & 0.0003 & 0.0008 & 0.0004 & 0.0007 & 0.0009 & 0.0008 & 0.0011 & 0.0005 & 0.0010 & 0.0013 \\
\hline \multicolumn{11}{|c|}{ Duration } \\
\hline & $O L F$ & $U N M$ & $S E L F$ & $I N F$ & FOR & $O L F$ & $U N M$ & $S E L F$ & $I N F$ & FOR \\
\hline & 3.5422 & 0.5135 & 3.4486 & 1.3789 & 4.1479 & 5.1611 & 0.4836 & 1.6884 & 1.3888 & 3.3600 \\
\hline & 0.0170 & 0.0036 & 0.0148 & 0.0051 & 0.0147 & 0.0174 & 0.0037 & 0.0072 & 0.0058 & 0.0142 \\
\hline \multicolumn{11}{|c|}{ Propensity Matrix } \\
\hline & $O L F$ & $U N M$ & $S E L F$ & $I N F$ & FOR & $O L F$ & $U N M$ & $S E L F$ & $I N F$ & $F O R$ \\
\hline \multirow[t]{2}{*}{$O L F$} & & 0.2374 & 0.1424 & 0.4330 & 0.1871 & & 0.2097 & 0.3834 & 0.2498 & 0.1571 \\
\hline & & 0.0038 & 0.0024 & 0.0035 & 0.0033 & & 0.0023 & 0.0018 & 0.0020 & 0.0017 \\
\hline \multirow[t]{2}{*}{$U N M$} & 0.0952 & & 0.1652 & 0.2779 & 0.4617 & 0.4083 & & 0.0735 & 0.1961 & 0.3221 \\
\hline & 0.0021 & & 0.0026 & 0.0036 & 0.0035 & 0.0037 & & 0.0025 & 0.0038 & 0.0036 \\
\hline \multirow[t]{2}{*}{$S E L F$} & 0.1470 & 0.1370 & & 0.4565 & 0.2594 & 0.6943 & 0.0250 & & 0.2084 & 0.0723 \\
\hline & 0.0018 & 0.0029 & & 0.0031 & 0.0027 & 0.0022 & 0.0016 & & 0.0022 & 0.0016 \\
\hline \multirow[t]{2}{*}{$I N F$} & 0.1247 & 0.1469 & 0.2676 & & 0.4609 & 0.2777 & 0.0979 & 0.1786 & & 0.4458 \\
\hline & 0.0014 & 0.0024 & 0.0019 & & 0.0024 & 0.0024 & 0.0025 & 0.0020 & & 0.0023 \\
\hline \multirow[t]{2}{*}{ FOR } & 0.0909 & 0.3451 & 0.1953 & 0.3687 & & 0.2454 & 0.2464 & 0.0696 & 0.4386 & \\
\hline & 0.0013 & 0.0029 & 0.0018 & 0.0025 & & 0.0028 & 0.0034 & 0.0017 & 0.0028 & \\
\hline
\end{tabular}

Standard Errors in italics below. Computations are based on 10.000 Monte Carlo draws 
Table 3c: Intensity Matrix, Duration and Propensity Matrix: Mexico

\begin{tabular}{|c|c|c|c|c|c|c|c|c|c|c|}
\hline \multicolumn{3}{|c|}{ Intensity Matrix } & \multicolumn{3}{|l|}{ Males } & \multicolumn{5}{|c|}{ Females } \\
\hline & $O L F$ & $U N M$ & $S E L F$ & $I N F$ & FOR & $O L F$ & $U N M$ & $S E L F$ & $I N F$ & FOR \\
\hline \multirow[t]{2}{*}{$O L F$} & -0.3881 & 0.1486 & 0.0668 & 0.0962 & 0.0766 & -0.1947 & 0.0547 & 0.0670 & 0.0393 & 0.0336 \\
\hline & 0.0021 & 0.0022 & 0.0013 & 0.0017 & 0.0013 & 0.0008 & 0.0007 & 0.0005 & 0.0004 & 0.0004 \\
\hline \multirow[t]{2}{*}{$U N M$} & 0.5898 & -1.9772 & 0.4076 & 0.4496 & 0.5303 & 1.3334 & -2.1968 & 0.1197 & 0.2983 & 0.4455 \\
\hline & 0.0091 & 0.0172 & 0.0087 & 0.0102 & 0.0084 & 0.0153 & 0.0200 & 0.0060 & 0.0089 & 0.0084 \\
\hline \multirow[t]{2}{*}{$S E L F$} & 0.0443 & 0.0418 & -0.3245 & 0.1506 & 0.0880 & 0.4510 & 0.0221 & -0.6157 & 0.1091 & 0.0336 \\
\hline & 0.0007 & 0.0010 & 0.0014 & 0.0013 & 0.0009 & 0.0031 & 0.0015 & 0.0034 & 0.0019 & 0.0011 \\
\hline \multirow[t]{2}{*}{$I N F$} & 0.1045 & 0.1220 & 0.4274 & -0.9778 & 0.3239 & 0.3499 & 0.0990 & 0.1767 & -0.9080 & 0.2825 \\
\hline & 0.0021 & 0.0032 & 0.0036 & 0.0049 & 0.0030 & 0.0042 & 0.0034 & 0.0029 & 0.0054 & 0.0033 \\
\hline \multirow[t]{2}{*}{ FOR } & 0.0209 & 0.0473 & 0.0664 & 0.0602 & -0.1948 & 0.0912 & 0.0364 & 0.0149 & 0.0561 & -0.1987 \\
\hline & 0.0004 & 0.0007 & 0.0006 & 0.0007 & 0.0009 & 0.0009 & 0.0008 & 0.0004 & 0.0007 & 0.0011 \\
\hline \multicolumn{11}{|c|}{ Duration } \\
\hline & $O L F$ & $U N M$ & $S E L F$ & $I N F$ & FOR & $O L F$ & $U N M$ & $S E L F$ & $I N F$ & FOR \\
\hline & 2.5766 & 0.5058 & 3.0813 & 1.0227 & 5.1330 & 5.1374 & 0.4552 & 1.6241 & 1.1013 & 5.0329 \\
\hline & 0.0141 & 0.0044 & 0.0134 & 0.0051 & 0.0228 & 0.0215 & 0.0041 & 0.0088 & 0.0066 & 0.0268 \\
\hline \multicolumn{11}{|c|}{ Propensity Matrix } \\
\hline & $O L F$ & $U N M$ & $S E L F$ & $I N F$ & FOR & $O L F$ & $U N M$ & $S E L F$ & $I N F$ & FOR \\
\hline \multirow[t]{2}{*}{$O L F$} & & 0.3828 & 0.1720 & 0.2478 & 0.1973 & & 0.2812 & 0.3444 & 0.2019 & 0.1726 \\
\hline & & 0.0049 & 0.0032 & 0.0041 & 0.0032 & & 0.0030 & 0.0021 & 0.0022 & 0.0019 \\
\hline \multirow[t]{2}{*}{$U N M$} & 0.2983 & & 0.2061 & 0.2274 & 0.2682 & 0.6070 & & 0.0545 & 0.1358 & 0.2028 \\
\hline & 0.0038 & & 0.0041 & 0.0046 & 0.0037 & 0.0044 & & 0.0027 & 0.0038 & 0.0034 \\
\hline \multirow[t]{2}{*}{$S E L F$} & 0.1364 & 0.1287 & & 0.4639 & 0.2710 & 0.7324 & 0.0359 & & 0.1771 & 0.0546 \\
\hline & 0.0021 & 0.0029 & & 0.0032 & 0.0026 & 0.0032 & 0.0024 & & 0.0028 & 0.0017 \\
\hline \multirow[t]{2}{*}{$I N F$} & 0.1069 & 0.1248 & 0.4371 & & 0.3313 & 0.3853 & 0.1090 & 0.1946 & & 0.3111 \\
\hline & 0.0022 & 0.0031 & 0.0029 & & 0.0027 & 0.0042 & 0.0036 & 0.0030 & & 0.0031 \\
\hline \multirow[t]{2}{*}{ FOR } & 0.1072 & 0.2426 & 0.3410 & 0.3092 & & 0.4588 & 0.1834 & 0.0752 & 0.2826 & \\
\hline & 0.0022 & 0.0035 & 0.0028 & 0.0031 & & 0.0041 & 0.0038 & 0.0022 & 0.0034 & \\
\hline
\end{tabular}

Standard Errors in italics below. Computations are based on 10.000 Monte Carlo draws 
Table 4: Mobility Indexes various Ages.

\begin{tabular}{|c|c|c|c|c|c|c|}
\hline & \multicolumn{2}{|c|}{ Argentina } & \multicolumn{2}{|c|}{ Brazil } & \multicolumn{2}{|c|}{ Mexico } \\
\hline & Male & Female & Male & Female & Male & Female \\
\hline \multirow[t]{2}{*}{ All } & 0.5724 & 0.6515 & 0.6973 & 0.7742 & 0.7724 & 0.8224 \\
\hline & 0.0111 & 0.0132 & 0.0057 & 0.0068 & 0.0037 & 0.0042 \\
\hline \multicolumn{7}{|c|}{$14-24$} \\
\hline & 0.7176 & 0.8033 & 0.8930 & 0.9608 & 0.8608 & 0.9240 \\
\hline & 0.0262 & 0.0403 & 0.0116 & 0.0132 & 0.0055 & 0.0064 \\
\hline \multicolumn{7}{|c|}{$24-40$} \\
\hline & 0.6515 & 0.7167 & 0.7383 & 0.7860 & 0.8129 & 0.8388 \\
\hline & 0.0273 & 0.0268 & 0.0110 & 0.0114 & 0.0080 & 0.0089 \\
\hline \multicolumn{7}{|c|}{$40-60$} \\
\hline & 0.5485 & 0.6153 & 0.6446 & 0.7742 & 0.7763 & 0.8554 \\
\hline & 0.0180 & 0.0195 & 0.0112 & 0.0209 & 0.0077 & 0.0115 \\
\hline \multicolumn{7}{|c|}{ Low Education } \\
\hline & 0.5918 & 0.7165 & 0.7311 & 0.8419 & 0.8012 & 0.8783 \\
\hline & 0.0172 & 0.0239 & 0.0077 & 0.0104 & 0.0050 & 0.0068 \\
\hline \multicolumn{7}{|c|}{ High Education } \\
\hline & 0.5655 & 0.6308 & 0.6478 & 0.7104 & 0.7774 & 0.8457 \\
\hline & 0.0140 & 0.0163 & 0.0089 & 0.0099 & 0.0059 & 0.0063 \\
\hline
\end{tabular}

Computations are based on 10.000 Monte Carlo draws Standard Errors below

\section{Table 5: New Unemployed by Sector of Origin}

\begin{tabular}{lccc}
\hline & Self-Employment & Informal Salaried & Formal Salaried \\
Argentina & $31 \%$ & $35 \%$ & $34 \%$ \\
Brazil & $15 \%$ & $24 \%$ & $61 \%$ \\
Mexico & $28 \%$ & $22 \%$ & $49 \%$ \\
\hline \hline
\end{tabular}

The results were computed using original sector sizes and the estimated intensities to

calculate flows into unemployment 
Table 6: Intensity Matrix, Duration and Propensity Matrix for Single Females: Argentina and Mexico

\begin{tabular}{|c|c|c|c|c|c|c|c|c|c|c|c|}
\hline \multicolumn{2}{|c|}{ Intensity Matrix } & \multicolumn{3}{|c|}{ Argentina } & \multicolumn{3}{|c|}{ Intensity Matrix } & \multicolumn{3}{|c|}{ Mexico } & \multirow[b]{2}{*}{ FOR } \\
\hline & $O L F$ & $U N M$ & SELF & $I N F$ & FOR & & $O L F$ & $U N M$ & SELF & $I N F$ & \\
\hline \multirow[t]{2}{*}{$O L F$} & -0.356 & 0.2515 & 0.0115 & 0.0583 & 0.0348 & $O L F$ & -0.3188 & 0.1305 & 0.0347 & 0.0762 & 0.0774 \\
\hline & 0.0139 & 0.0156 & 0.0045 & 0.0092 & 0.0058 & & 0.0021 & 0.0022 & 0.0008 & 0.0013 & 0.0012 \\
\hline \multirow[t]{2}{*}{$U N M$} & 0.4661 & -1.0855 & 0.0749 & 0.3596 & 0.1848 & $U N M$ & 1.118 & -2.0517 & 0.0978 & 0.305 & 0.5309 \\
\hline & 0.0382 & 0.0587 & 0.0204 & 0.0421 & 0.0244 & & 0.0187 & 0.0253 & 0.0065 & 0.0123 & 0.012 \\
\hline \multirow[t]{2}{*}{$S E L F$} & 0.1352 & 0.1833 & -0.7619 & 0.3634 & 0.08 & SELF & 0.2736 & 0.0475 & -0.5897 & 0.1779 & 0.0908 \\
\hline & 0.0369 & 0.0516 & 0.0658 & 0.059 & 0.0253 & & 0.0059 & 0.0045 & 0.0071 & 0.0052 & 0.0037 \\
\hline \multirow[t]{2}{*}{$I N F$} & 0.157 & 0.3946 & 0.1854 & -0.8763 & 0.1393 & $I N F$ & 0.2914 & 0.1103 & 0.1156 & -0.8887 & 0.3713 \\
\hline & 0.0312 & 0.0493 & 0.0287 & 0.0528 & 0.0234 & & 0.0056 & 0.0053 & 0.0034 & 0.0075 & 0.0051 \\
\hline \multirow[t]{2}{*}{$F O R$} & 0.0151 & 0.0969 & 0.021 & 0.0528 & -0.1857 & FOR & 0.0703 & 0.0519 & 0.0148 & 0.0735 & -0.2105 \\
\hline & 0.0069 & 0.0126 & 0.0061 & 0.0102 & 0.0123 & & 0.0013 & 0.0014 & 0.0006 & 0.0013 & 0.0017 \\
\hline \multirow[t]{3}{*}{ Durati } & & & & & & Duratio & & & & & \\
\hline & $O L F$ & $U N M$ & SELF & $I N F$ & FOR & & $O L F$ & $U N M$ & $S E L F$ & $I N F$ & FOR \\
\hline & 0.1104 & 0.0497 & 0.1143 & 0.069 & 0.3622 & & 0.0208 & 0.006 & 0.0205 & 0.0095 & 0.038 \\
\hline \multicolumn{6}{|c|}{ Propensity Matrix } & \multicolumn{6}{|c|}{ Propensity Matrix } \\
\hline & $O L F$ & $U N M$ & $S E L F$ & $I N F$ & FOR & & $O L F$ & $U N M$ & $S E L F$ & $I N F$ & FOR \\
\hline \multirow[t]{2}{*}{$O L F$} & & 0.7062 & 0.0323 & 0.1638 & 0.0977 & $O L F$ & & 0.4093 & 0.109 & 0.2391 & 0.2426 \\
\hline & & 0.0305 & 0.0126 & 0.0258 & 0.0161 & & & 0.0054 & 0.0024 & 0.0039 & 0.0039 \\
\hline \multirow[t]{2}{*}{$U N M$} & 0.4295 & & 0.069 & 0.3311 & 0.1704 & $U N M$ & 0.5449 & & 0.0477 & 0.1486 & 0.2588 \\
\hline & 0.0286 & & 0.0186 & 0.0322 & 0.021 & & 0.0059 & & 0.0031 & 0.0056 & 0.0052 \\
\hline \multirow[t]{2}{*}{ SELF } & 0.1775 & 0.2408 & & 0.4766 & 0.105 & $S E L F$ & 0.4639 & 0.0805 & & 0.3017 & 0.1539 \\
\hline & 0.0466 & 0.0655 & & 0.0631 & 0.0325 & & 0.0085 & 0.0076 & & 0.008 & 0.006 \\
\hline \multirow[t]{2}{*}{$I N F$} & 0.1793 & 0.4501 & 0.2115 & & 0.1591 & $I N F$ & 0.3279 & 0.1242 & 0.1301 & & 0.4178 \\
\hline & 0.0345 & 0.0474 & 0.0295 & & 0.0261 & & 0.0057 & 0.0058 & 0.0037 & & 0.0047 \\
\hline \multirow[t]{2}{*}{ FOR } & 0.081 & 0.5218 & 0.1129 & 0.2844 & & FOR & 0.3341 & 0.2464 & 0.0703 & 0.3492 & \\
\hline & 0.0369 & 0.0601 & 0.0322 & 0.0513 & & & 0.0058 & 0.0063 & 0.0029 & 0.0053 & \\
\hline
\end{tabular}


Figure 1: Absolute Mean Duration in Each Sector

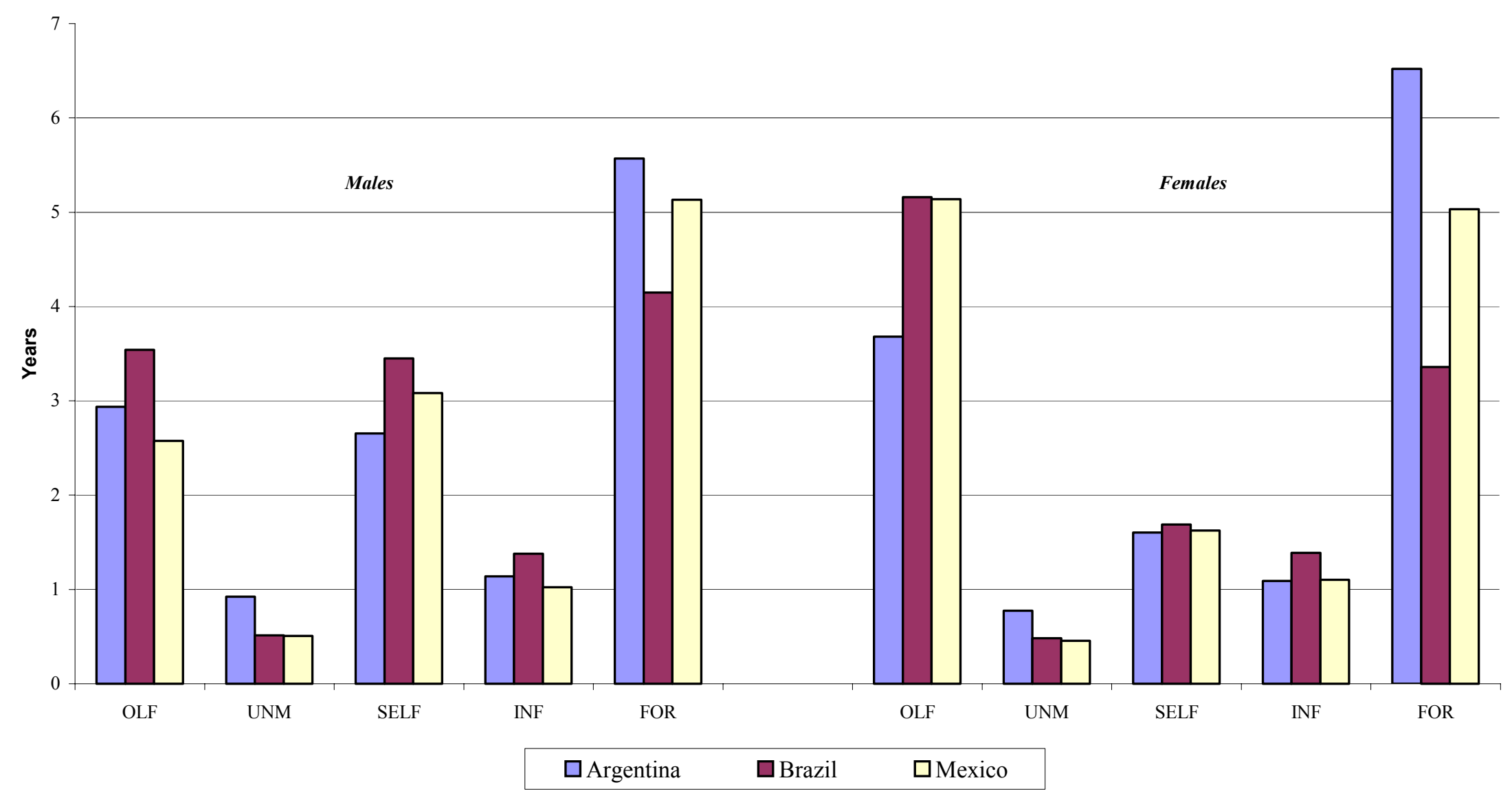


Figure 2: Propensities into Informal Salaried
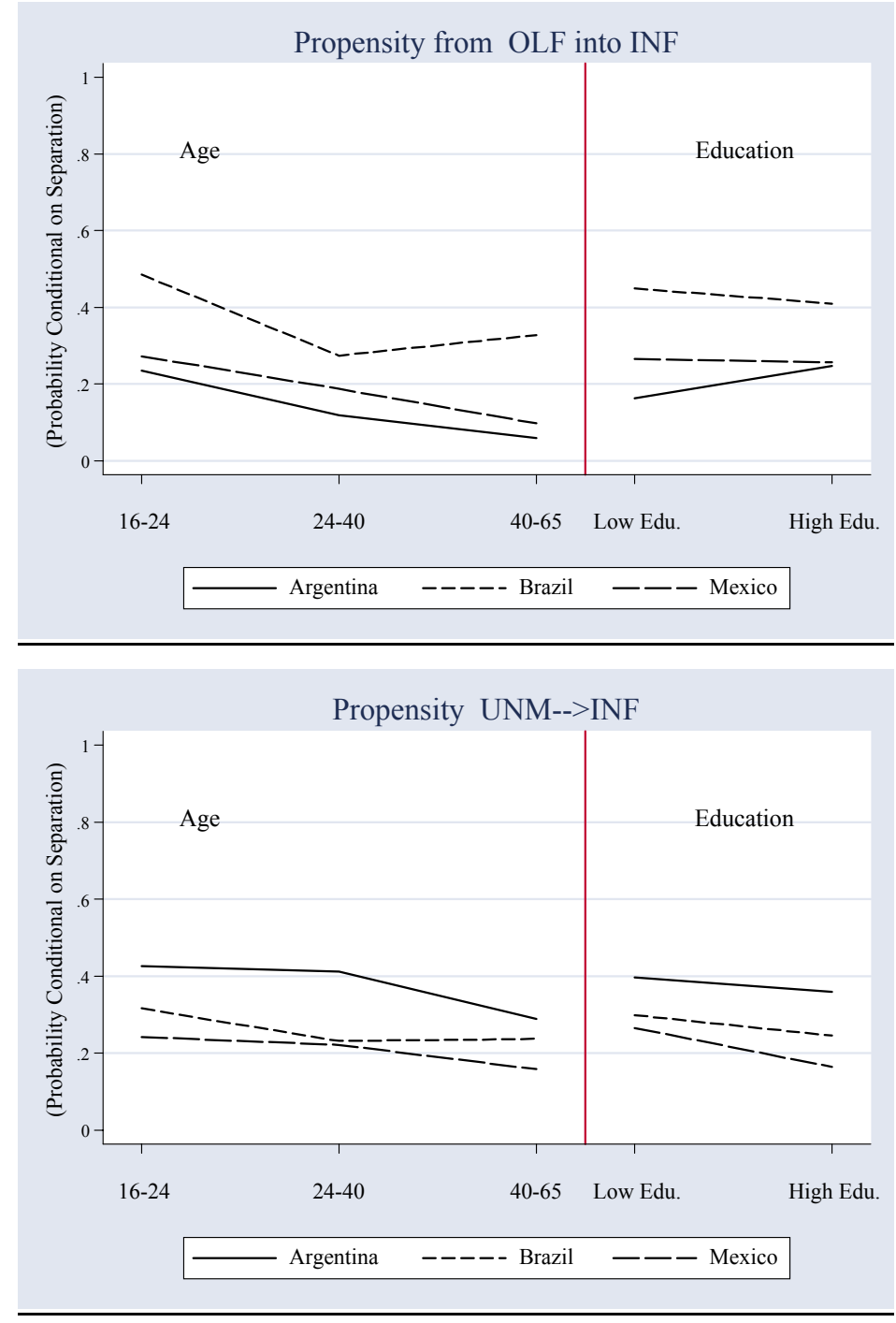
Figure 3: Mean Duration time in Formal Sector, Self-Employment, Informal Salaried.
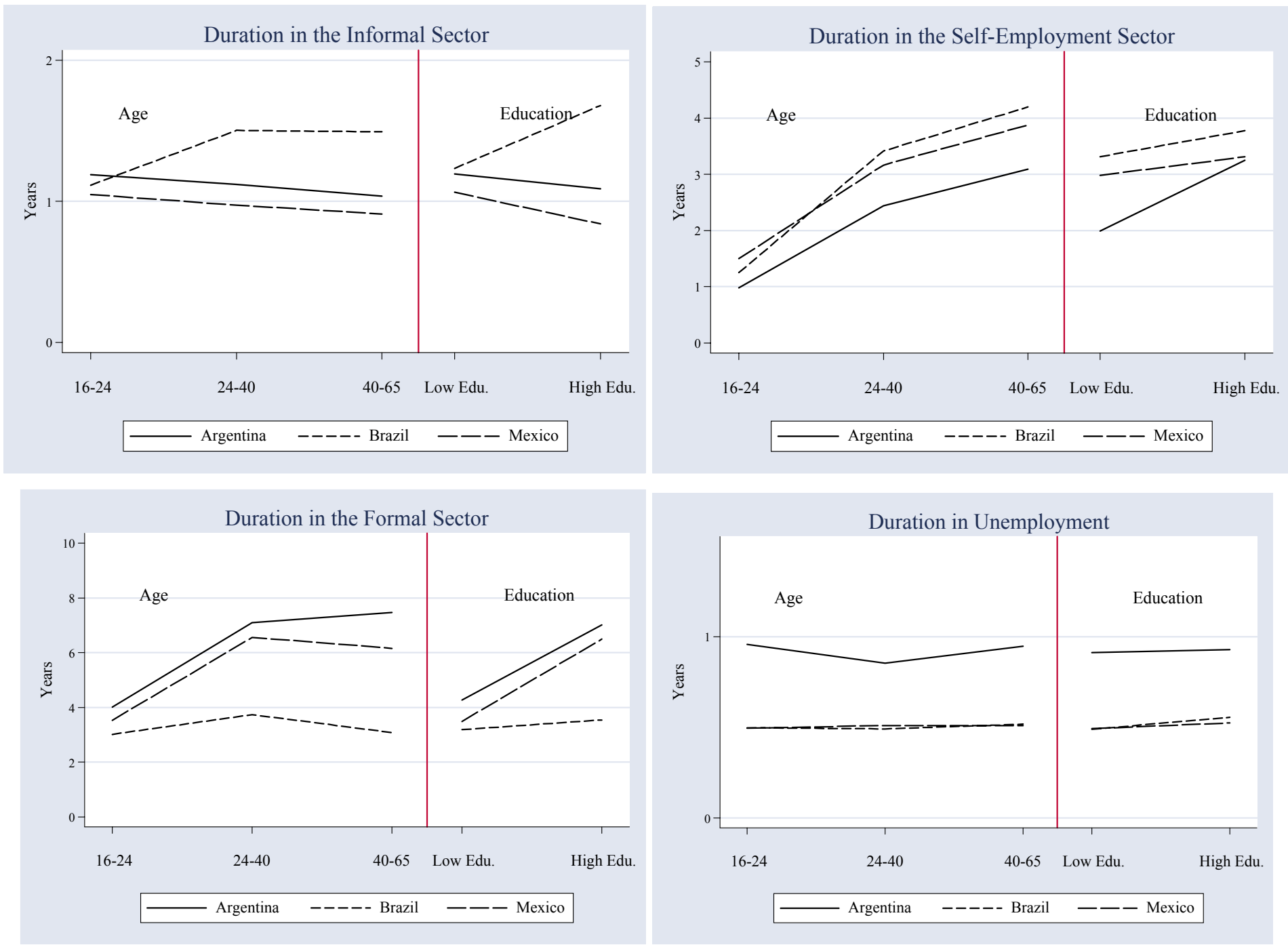


\section{Figure 4: Propensities to Self-Employment from different Sectors.}
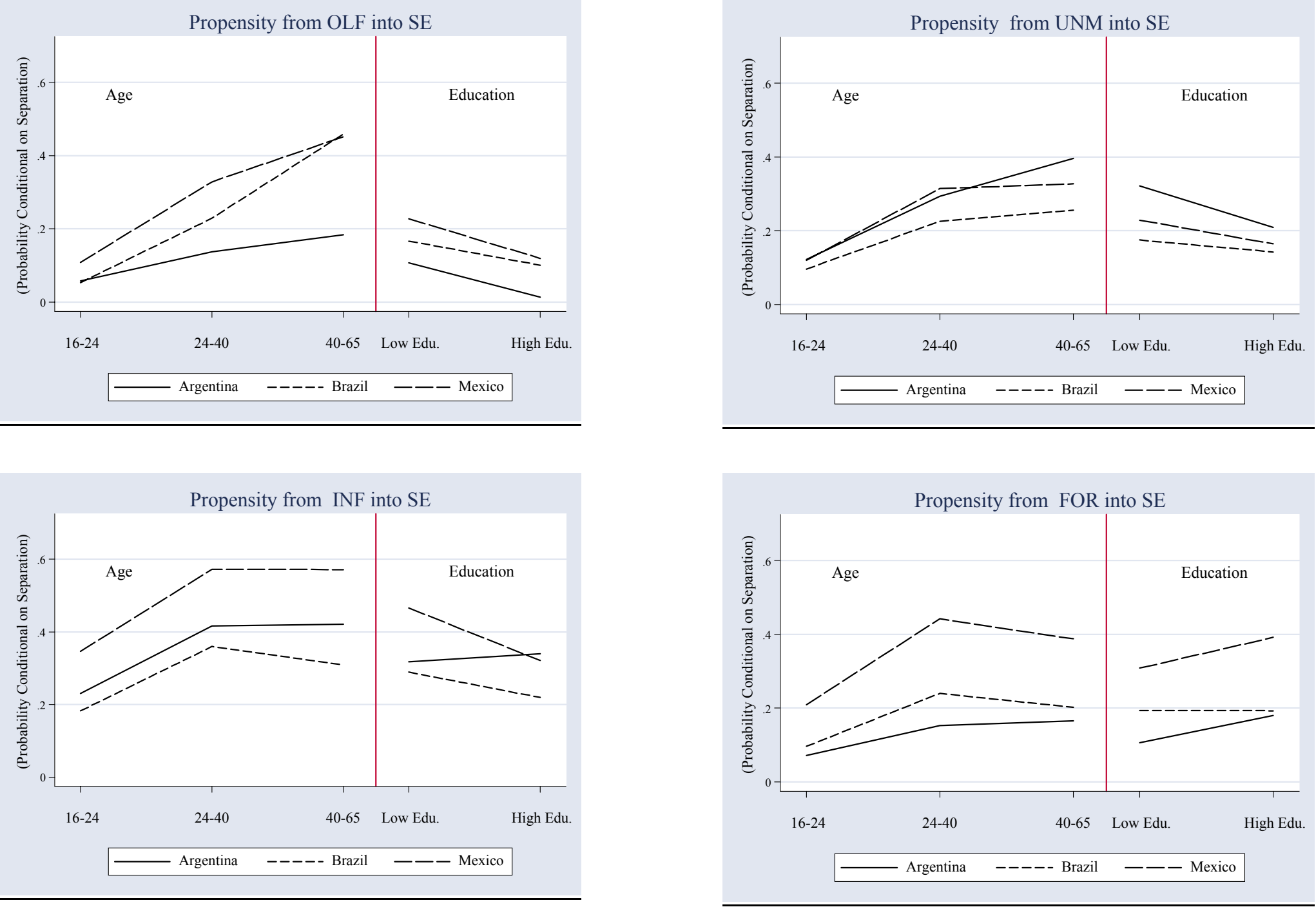
Figure 5: Shares of Formal Informal Sector and Unemployment.

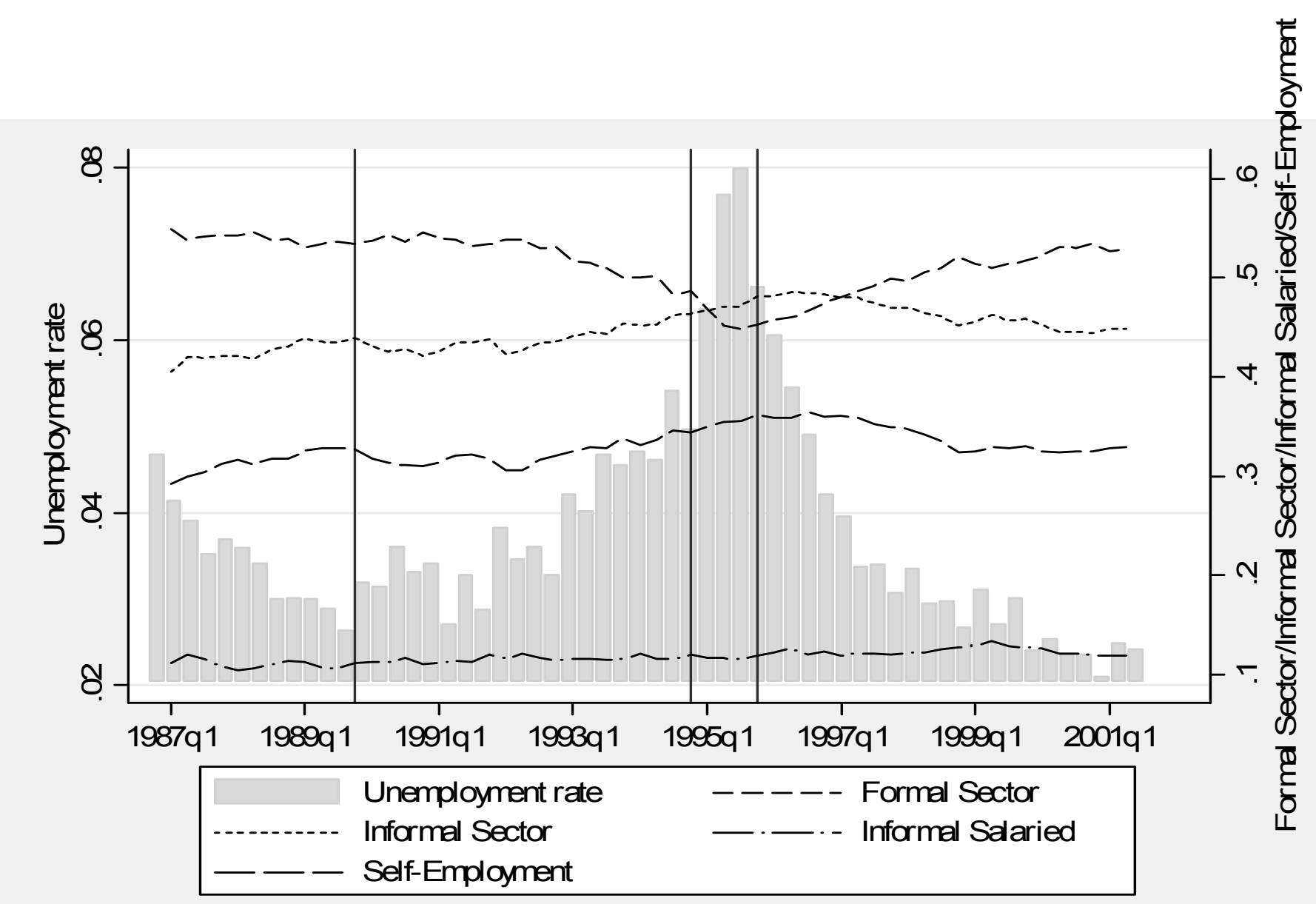


Figure 6 : Duration In the Formal Salaried, Informal Salaried and Self-Employment Sectors

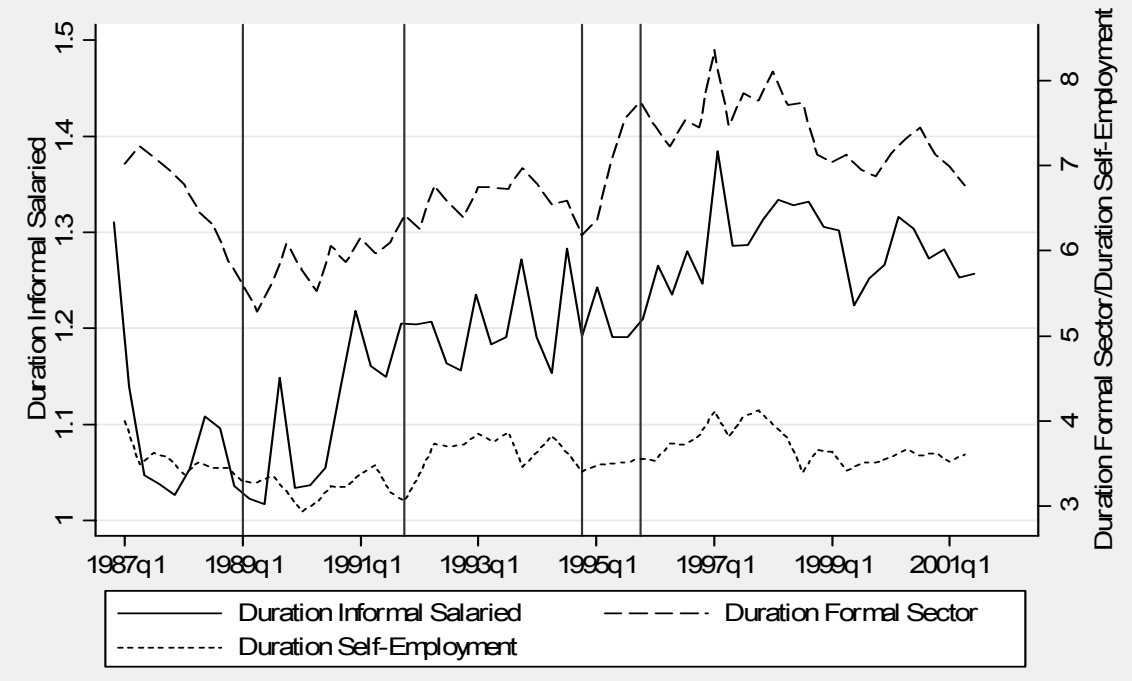

Figure 7 : Duration OLF and Unemployment

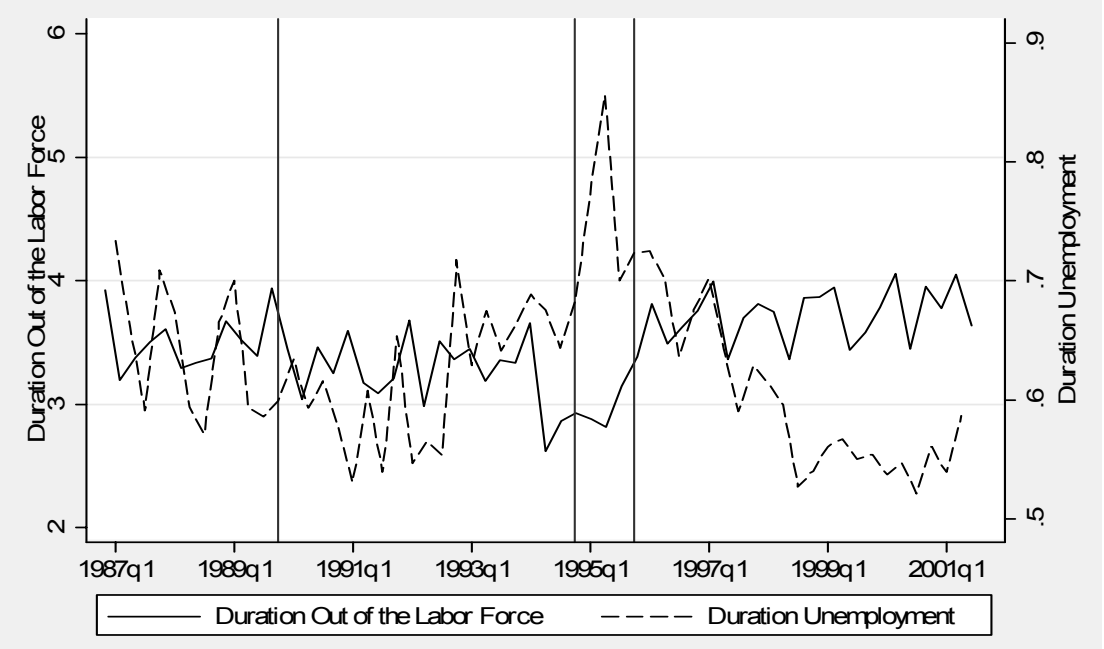


Figure 8 : Transitions between Formal Salaried, Informal Salaried and Self-Employment
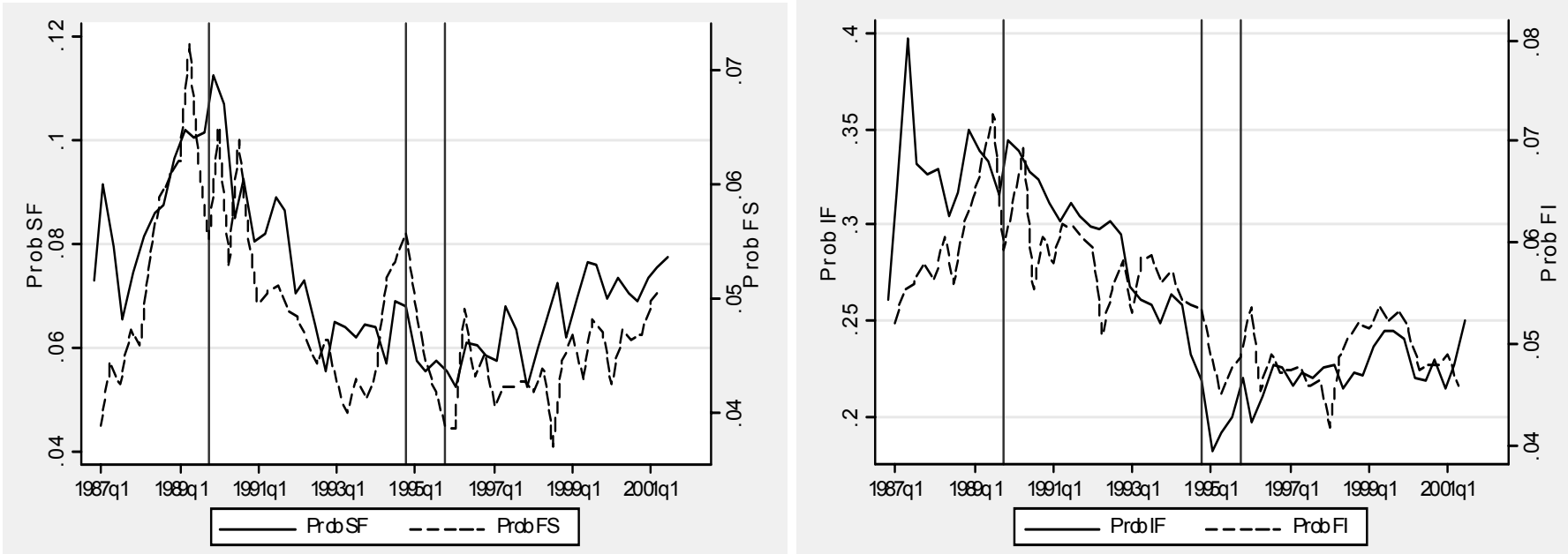

Figure 9: Propensities from and to Formal Salaried
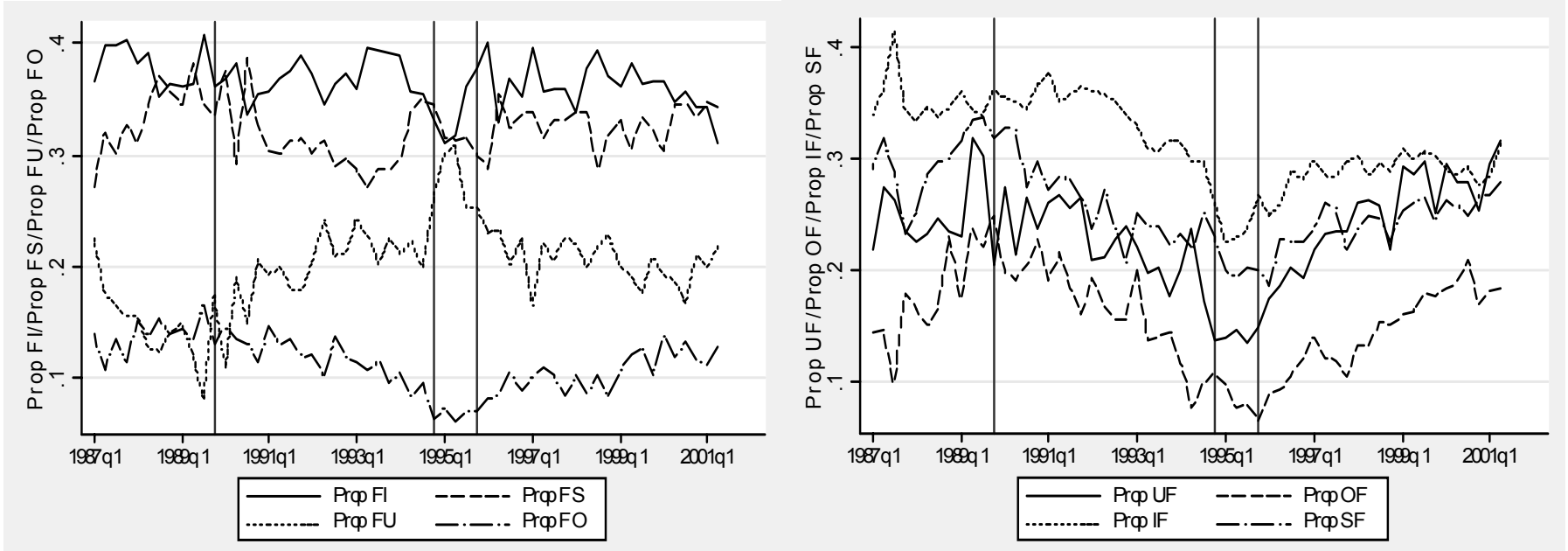
Figure 10: Transitions between Formal Salaried and Unemployment and Out of the Labor Force
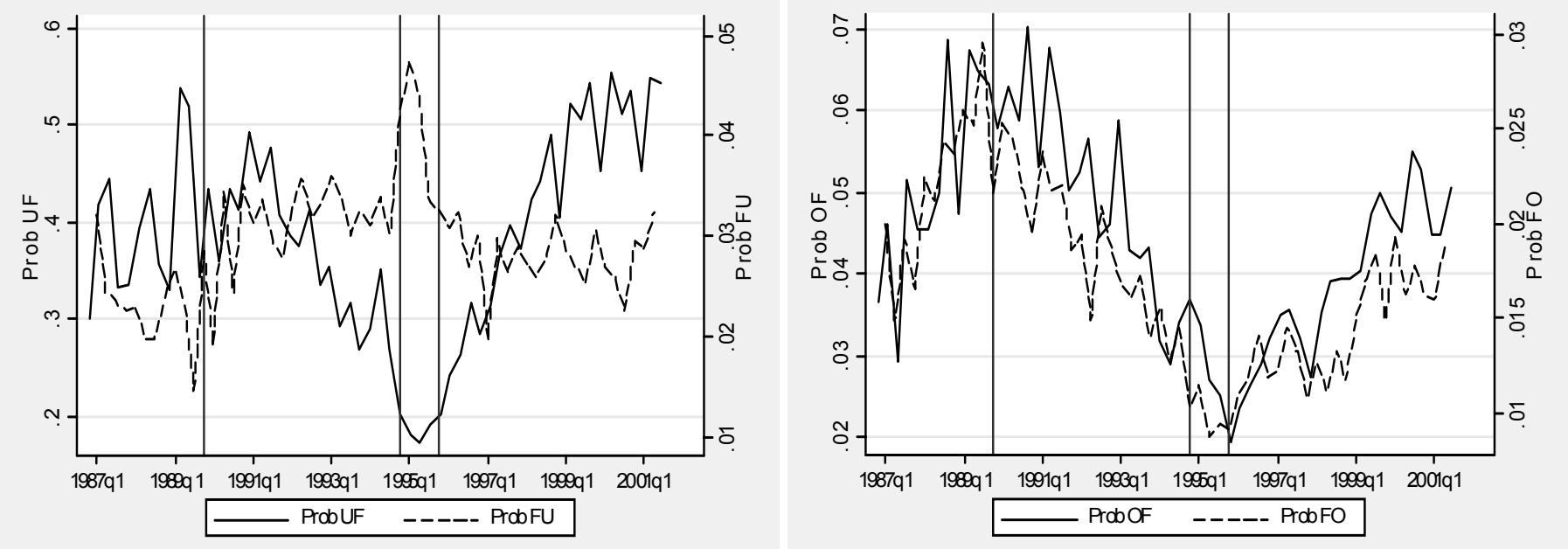
Figure 11: Transitions To Unemployment and Out of the Labor Force
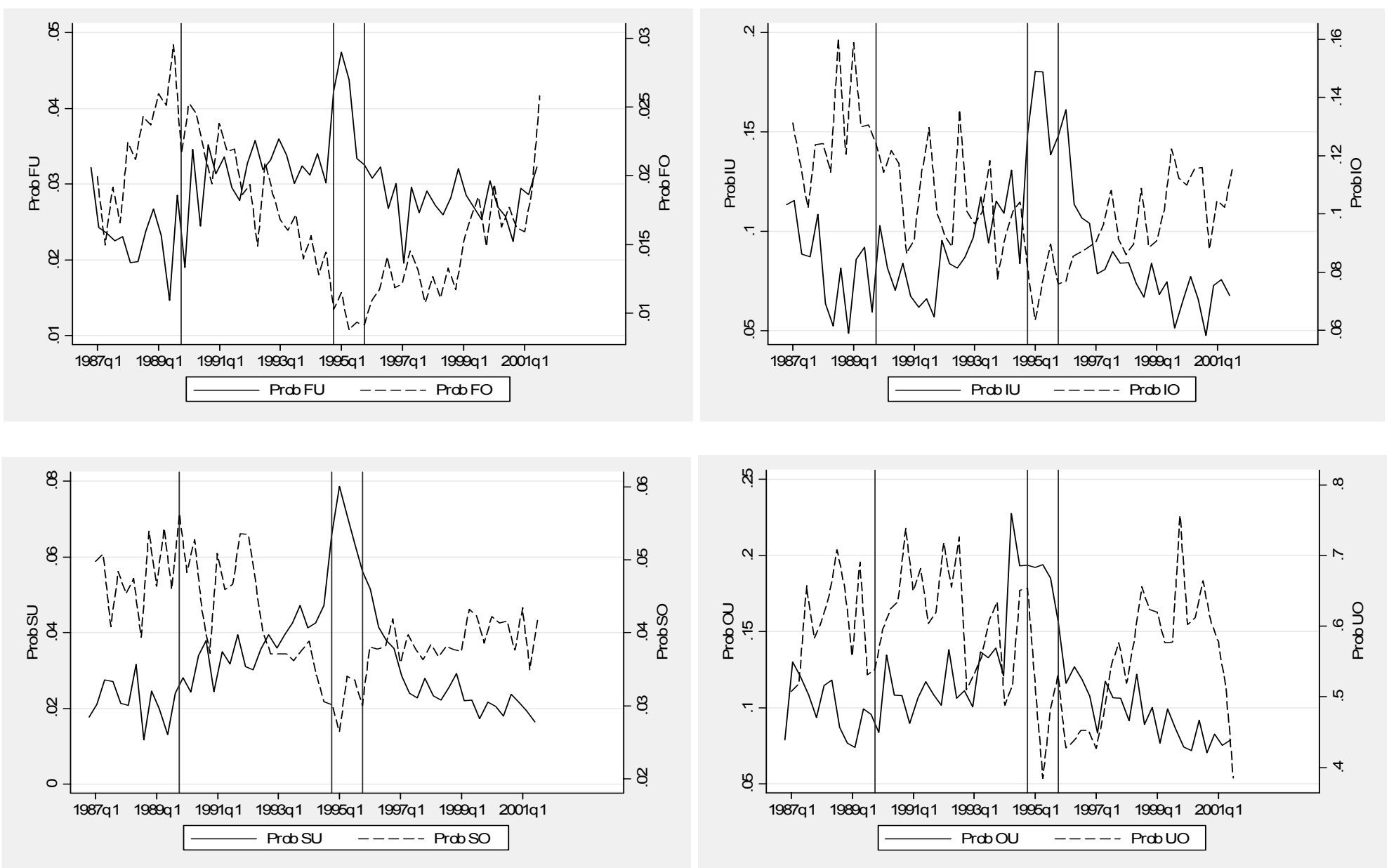